\title{
Review \\ Secondary Metabolites of Plants as Modulators of Endothelium Functions
}

\author{
Anna Bartáková ${ }^{1}$ and Marie Nováková ${ }^{1,2, *}$ \\ 1 Department of Physiology, Faculty of Medicine, Masaryk University, 62500 Brno, Czech Republic; \\ anna.bartakova@med.muni.cz \\ 2 International Clinical Research Center, St. Anne's University Hospital Brno, 65691 Brno, Czech Republic \\ * Correspondence: majka@med.muni.cz
}

Citation: Bartáková, A.; Nováková, M. Secondary Metabolites of Plants as Modulators of Endothelium Functions. Int. J. Mol. Sci. 2021, 22, 2533. https://doi.org/10.3390/ ijms22052533

Academic Editor: Bartosz Jan Płachno

Received: 20 January 2021

Accepted: 25 February 2021

Published: 3 March 2021

Publisher's Note: MDPI stays neutral with regard to jurisdictional claims in published maps and institutional affiliations.

Copyright: (c) 2021 by the authors. Licensee MDPI, Basel, Switzerland. This article is an open access article distributed under the terms and conditions of the Creative Commons Attribution (CC BY) license (https:/ / creativecommons.org/licenses/by/ $4.0 /)$.

\begin{abstract}
According to the World Health Organization, cardiovascular diseases are the main cause of death worldwide. They may be caused by various factors or combinations of factors. Frequently, endothelial dysfunction is involved in either development of the disorder or results from it. On the other hand, the endothelium may be disordered for other reasons, e.g., due to infection, such as COVID-19. The understanding of the role and significance of the endothelium in the body has changed significantly over time-from a simple physical barrier to a complex system encompassing local and systemic regulation of numerous processes in the body. Endothelium disorders may arise from impairment of one or more signaling pathways affecting dilator or constrictor activity, including nitric oxide-cyclic guanosine monophosphate activation, prostacyclin-cyclic adenosine monophosphate activation, phosphodiesterase inhibition, and potassium channel activation or intracellular calcium level inhibition. In this review, plants are summarized as sources of biologically active substances affecting the endothelium. This paper compares individual substances and mechanisms that are known to affect the endothelium, and which subsequently may cause the development of cardiovascular disorders.
\end{abstract}

Keywords: endothelium; vasoactive substances; vasodilation; vasoconstriction; nitric oxide

\section{Introduction}

According to the World Health Organization (WHO), almost 18 million people died worldwide in 2017 due to cardiovascular disorders. Numerous experimental and clinical studies are, therefore, focused on the cardiovascular system under both physiological and pathological conditions.

The cardiovascular system consists of the heart and vessels of various types. Three layers form a typical vessel: the tunica intima, tunica media, and tunica adventitia. The thickness ratio of a vessel wall depends on the functional requirements of that particular part of circulation system. Nevertheless, endothelial cells are a standard part of the tunica intima in any vessel.

\section{The Endothelium: From a Simple Barrier to a Specialized Organ \\ 2.1. Morphology of the Endothelium}

A single layer of flat endothelial cells covers the inner surface of a vessel, which is in direct contact with the blood. Thus, this inner lining provides an anticoagulant barrier between the vessel wall and blood. All endothelial cells form a large organ consisting of approximately $1-6 \times 10^{13}$ of cells, a mass of almost one kilogram [1].

The endothelium originates from the splanchnopleuric mesoderm [1]. Vascular endothelial growth factor (VEGF) and its high-affinity flk-1 and flt-1 receptor tyrosine kinases represent a paracrine signaling system that is critical for endothelial cell differentiation and vascular system development [2,3]. It has been proven that VEGF is the only specific mitogen for endothelial cells. It stimulates their growth, inhibits apoptosis, increases vascular 
permeability in various tissues, and promotes vasculogenesis and angiogenesis. Angiogenesis plays a protective role in coronary artery disease and myocardial infarction [4].

Endothelial cells consist of four basic compartments: the glycocalyx, cell cortex, cytoplasm, and nucleus (Figure 1). The structure and mechanical properties of these compartments directly affect physiological processes [1]. The endothelial glycocalyx is a thick, carbohydrate-rich layer that surrounds the endothelial lumen surface; it is composed of proteoglycans and glycoproteins. On the inner side of a cell membrane, the cell cortex is found, containing actin organized in a dynamic net. Actin fibers represent a support network for the plasma membrane and membrane proteins. The cell is also penetrated by actin microtubules and intermediate filaments. All components of the cell cytoskeleton are associated with the nucleus. Mechanical stimuli perceived by actin fibers, microtubules, or intermediate filaments are integrated in the nucleus [5]. Endothelial cells contain so-called Weibel-Palade bodies, measuring $0.1 \mu \mathrm{m}$ wide and $0.3 \mu \mathrm{m}$ long. These membrane-bound structures are a kind of storage organelle for von Willebrand's factor (vWf) (Figure 1) [1].

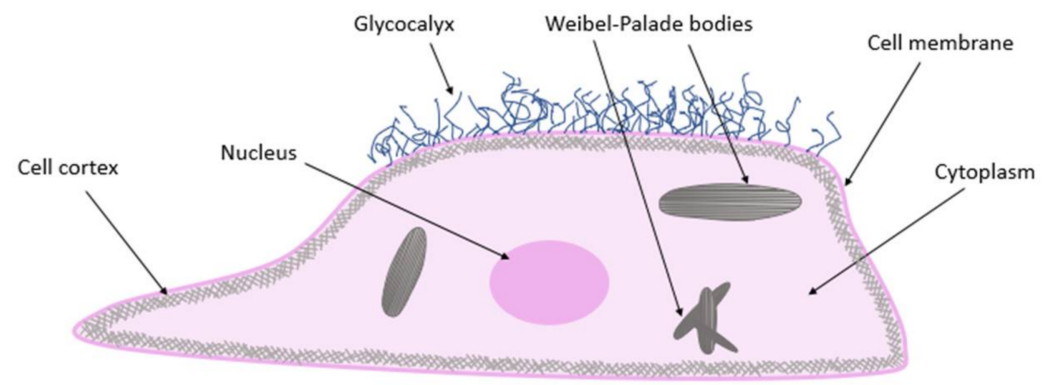

Figure 1. Endothelial cell structure.

\subsection{Physiological Roles of Endothelium}

For a long time, the role of the simple barrier was attributed to the endothelium. Since then, its concept has changed significantly and new functions of endothelial cells have been reported. It is now considered a specialized organ with numerous physiological functions [1].

First of all, the barrier function of the endothelium is viewed in a less static way than in the original concept, where the endothelium was believed to simply separate blood from the surrounding tissues. Nowadays, it is considered a dynamic barrier, the integrity of which is essential for maintaining physiological blood flow. On the other hand, endothelial cells communicate among themselves on one side and with circulating blood elements on the other side; the latter involves thrombocytes and leukocytes. Communication with other cells, even distant ones, via various paracrine and endocrine substances has also been described. All of these cells, cooperatively with the blood flow, affect the behavior of the endothelium [6].

Based on the above, it can be presumed that both endothelial cell injury and its dysfunction may lead to a number of pathological situations. Endothelial dysfunction results in various seemingly unrelated pathological processes, such as loss of semipermeable membrane function, hyperlipoproteinemia (often accompanied by atherogenesis), diabetes mellitus, vascular spasms, and arterial hypertension. Together with certain risk factors (e.g., smoking), these processes progress to uniform vascular changes. Subsequent organ hypoperfusion leads to failure in the target structure, for example heart failure [1].

The basic humoral and metabolic functions of the endothelium are summarized in Figure 2. Various types of autocrine, paracrine, and endocrine communication systems are presented. 


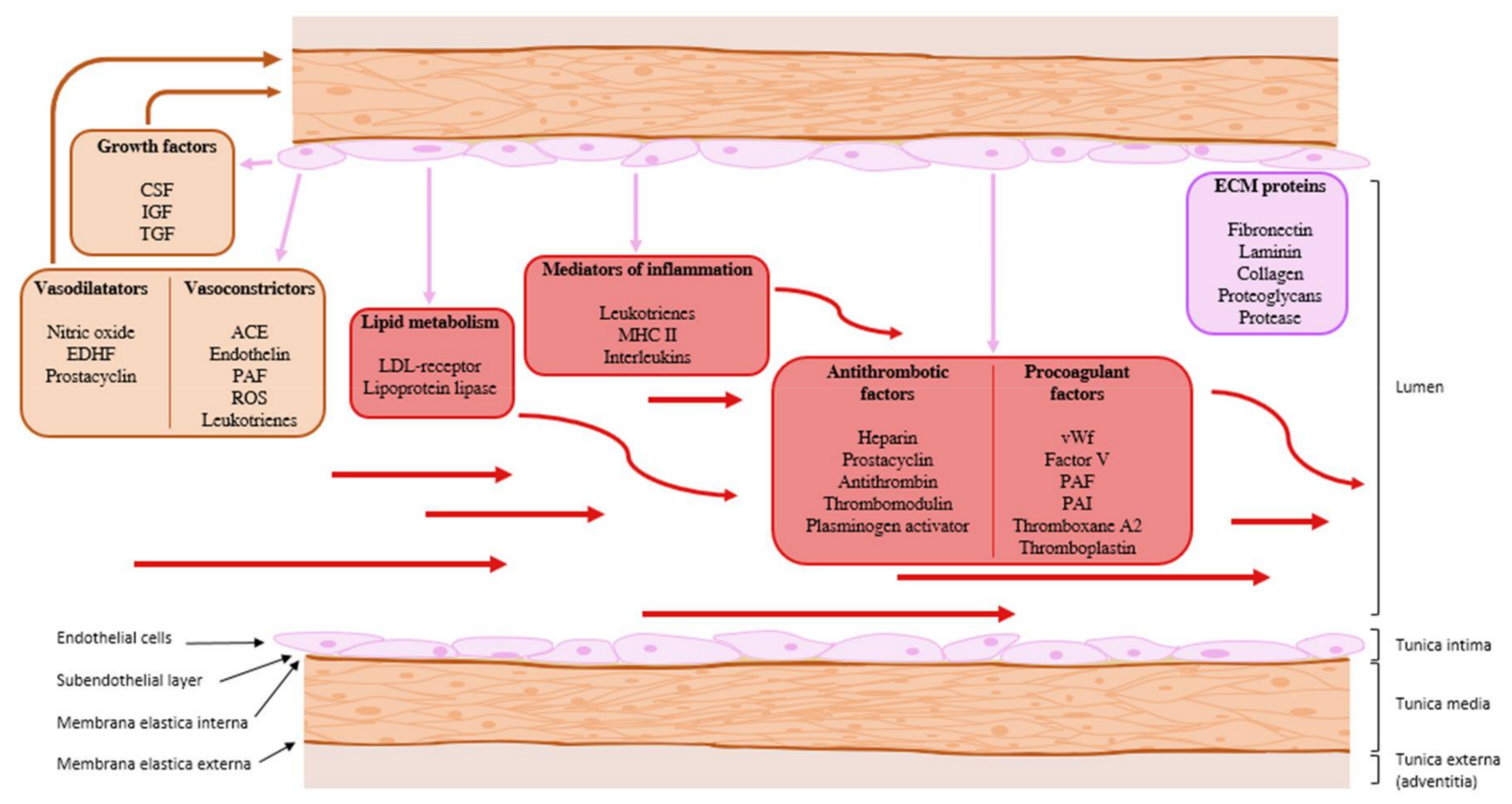

Figure 2. The basic humoral and metabolic functions of the endothelium. ACE: angiotensin converting enzyme; CSF: colony-stimulating factor; ECM: extracellular matrix; EDH: endothelium-derived hyperpolarization; IGF: insulin-like growth factor; LDL receptor: low-density lipoprotein receptor; MHC II: major histocompatibility complex type 2; PAF: platelet-activating factor; PAI: plasminogen activator inhibitor; ROS: reactive oxygen species; TGF: transforming growth factor; vWf: von Willebrand's factor. Purple arrow: paracrine communication, red arrow: endocrine communication.

\subsubsection{Vascular Tone Regulation}

The endothelium is a site of production or modification of numerous vasodilatory and vasoconstrictory substances, which regulate the vascular tone via several pathways, namely nitric oxide-cyclic guanosine monophosphate (NO-cGMP) activation, prostacyclincyclic adenosine monophosphate $\left(\mathrm{PGI}_{2}-\mathrm{cAMP}\right)$ activation, inhibition of phosphodiesterase (PDE), and activation of $\mathrm{K}^{+}$channels or inhibition of intracellular $\mathrm{Ca}^{2+}$ levels (Figure 3).

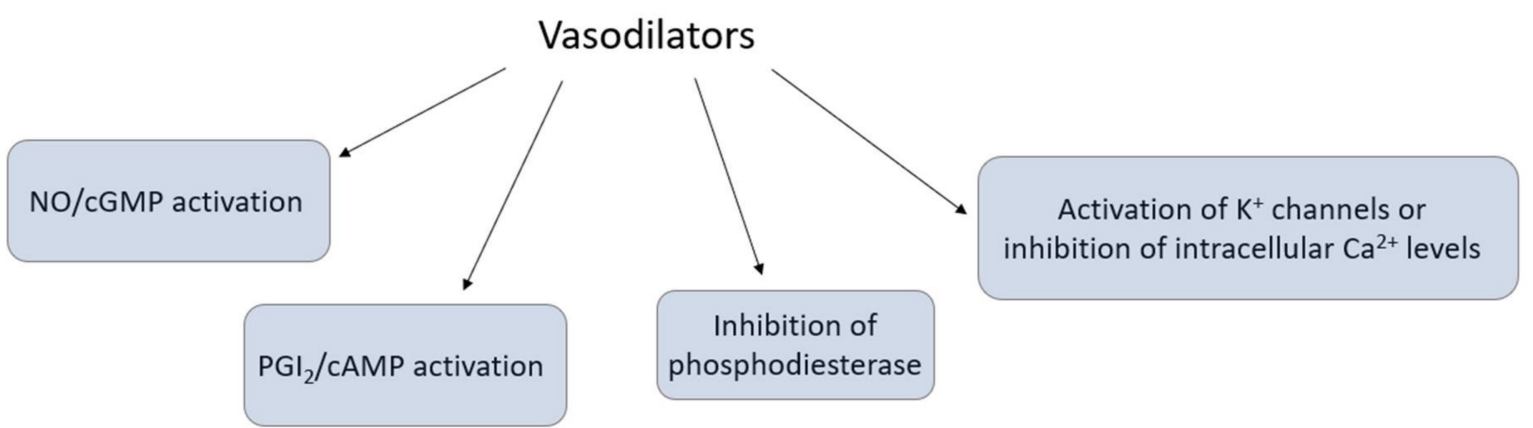

Figure 3. Endothelial regulation of vascular tone via several pathways.

The endothelial cell reacts to physical and chemical stimuli from the circulation. Physical (hemodynamic) factors increase the sensory tension of endothelial cells, which depends on the blood flow velocity in the vessels. Chemical stimuli are represented by vasoactive substances (e.g., adenosine monophosphate, bradykinin, histamine), neurotransmitters (e.g., acetylcholine), hormones (e.g., antidiuretic hormone, angiotensin), coagulation factors, and substances produced by platelets (e.g., thrombin) [1].

In cases of locally increased blood flow, the local regulatory system is activated, which results in endothelium-mediated vasodilation. Nitric oxide (NO), prostacyclin $\left(\mathrm{PGI}_{2}\right)$, or endothelium-derived hyperpolarization (EDH) is secreted from the endothelium due to the increased shear stress. This may be a form of endothelium protection, resulting from 
increased blood flow. In the case of a turbulent flow, the risk of damage to the endothelium and consequent thrombus formation increases. NO mainly regulates the tonus of relatively large conduit vessels. On the contrary, EDH mediates vasodilation, especially in small resistance vessels in the microcirculation. Prostacyclins play a small but constant role, independent of vessel size. Furthermore, metabolic regulation can occur when substances (e.g., $\left.\mathrm{O}_{2}\right)$ that are necessary to ensure metabolism or emerging catabolites $\left(\mathrm{CO}_{2}\right.$, lactic acid, adenosine, and others) act on vascular smooth muscle and affect its tone, either directly or more often through endothelial receptors [7-9].

\section{Angiotensin-Converting Enzyme}

A detailed view of the intracellular mediation of the effects of vasoactive substances brings about a thought-provoking idea: a key player in this game is angiotensin-converting enzyme (ACE), also known as kininase II. It is produced by the vascular endothelium and plays a central role in the renin-angiotensin-aldosterone system (RAAS). ACE converts angiotensin I (AT I) to octapeptide angiotensin II (AT II), which is a very potent vasoconstrictor (Figure 4) [10]. AT II increases the production of reactive oxygen species (ROS) via increasing NADPH oxidase activity. Increased levels of endothelial ROS lead to rapid inactivation or degradation of $\mathrm{NO}$, and at the same time to endothelial nitric oxide synthase (eNOS) and prostacyclin synthase (PGIS) inhibition [10-14]. It is important to mention that NADPH oxidase activation is one of the pathways involved in production of endothelium-derived $\mathrm{H}_{2} \mathrm{O}_{2}\left(\mathrm{E}-\mathrm{D} \mathrm{H}_{2} \mathrm{O}_{2}\right)$ hyperpolarizing factor, a substance with high vasodilating potency [7].

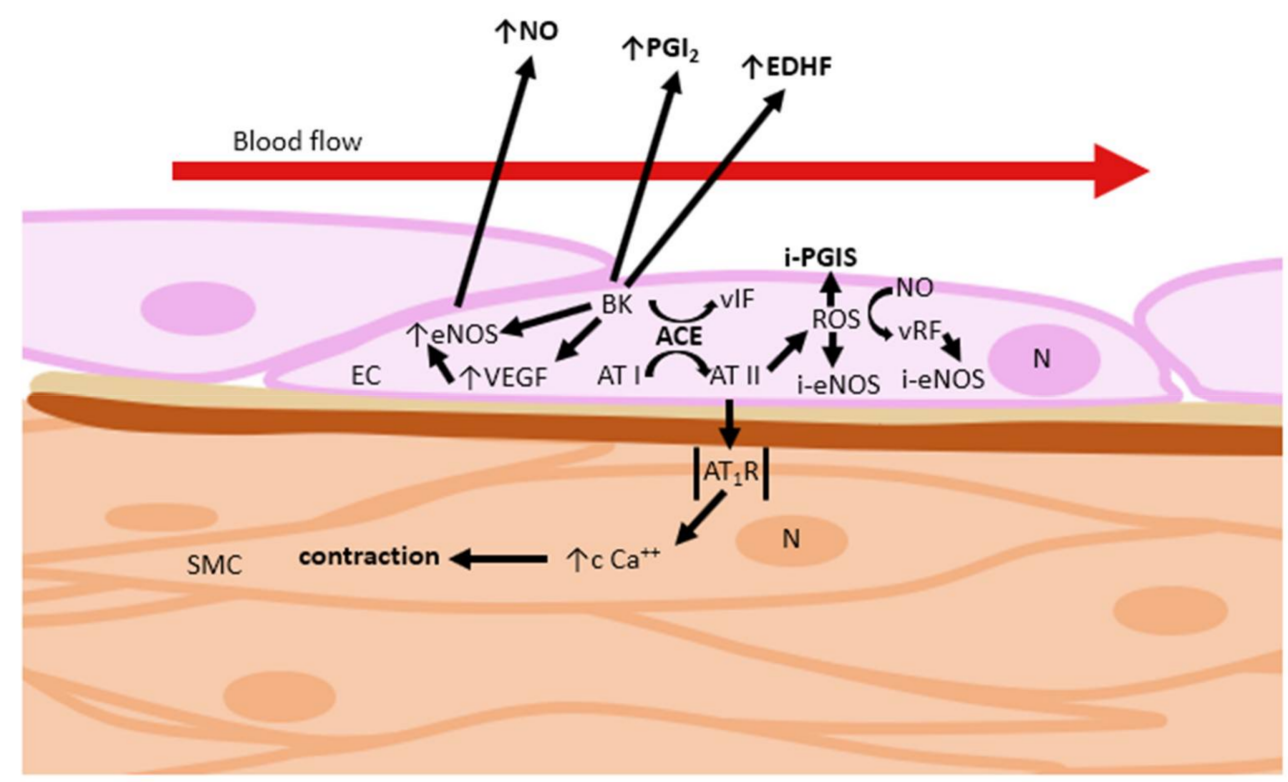

Figure 4. Regulation of vascular tone via ACE pathway. AT I: angiotensin I; AT II: angiotensin II; ACE: angiotensin-converting enzyme; $\mathrm{AT}_{1} \mathrm{R}$ : angiotensin type-1 receptor; $\mathrm{BK}$ : bradykinin; $\mathrm{EC}$ : endothelial cell; eNOS: endothelial NO synthase; i-eNOS: endothelial NO synthase inhibition; i-PGIS: prostacyclin synthase inhibition; NO: nitric oxide; N: nucleus; ROS: reactive oxygen species; SMC: smooth muscle cell; vIF: various inactive fragments; vRF: various reactive fragments.

AT II itself increases blood pressure, not only through vasoconstriction, but also through stimulation of the sympathetic system via the synthesis of aldosterone. AT II also acts as an inducer of growth, cell migration, and cell mitosis in vascular smooth muscle. It also increases the synthesis of type I and III collagen in fibroblasts, resulting in thickening of the blood vessel wall and myocardium and fibrosis. These effects are mediated by receptor type I for angiotensin II $\left(\mathrm{AT}_{1} \mathrm{R}\right)$ and can be blocked by $\mathrm{AT}_{1} \mathrm{R}$ blockers known as the "sartan" family $[15,16]$. Receptor type II for AT II mediates the opposite effect, e.g., inhibition of cell 
proliferation in coronary endothelial cells [17]. AT II may trigger endothelial cell apoptosis, mediated either by generation of ROS or by inhibiting the function of the antiapoptotic protein B-cell lymphoma 2 [11]. The regulation of its effect is an essential part of the clinical practice of treating hypertension [10].

Moreover, ACE degrades kinins. Bradykinin stimulates NO and $\mathrm{PGI}_{2}$ release [10-12,14] and increases vascular permeability [18]. The effect of bradykinin on NO release is mediated by $B_{2}$ receptor $[10-12,14]$. Angiotensin-converting enzyme inhibitors (iACEs) potentiate the actions of bradykinin by reducing its degradation [11], which leads to higher bradykinin levels. On the contrary, blocking the effect of AT II through $\mathrm{AT}_{1} \mathrm{R}$ does not affect the level of bradykinin [19].

At this point, we would like to emphasize that iACEs affect the delicate physiological balance between $\mathrm{NO}$ and $\mathrm{EDH}[7]$.

Nitric Oxide-Cyclic Guanosine Monophosphate Activation Pathway

Endothelium-derived relaxing factor $(\mathrm{NO})$ is produced from the amino acid arginine, which is transferred into the amino acid citrulline. This reaction is catalyzed by the enzyme nitric oxide synthase (NOS).

Nitric oxide is one of the three gasotransmitters, along with carbon monoxide (CO) and hydrogen sulphide $\left(\mathrm{H}_{2} \mathrm{~S}\right)$, which are critical for cardiovascular homeostasis [20]. NO acts as a mediator, having a local vasodilatory effect on vascular smooth muscle. NOS exists in three isoforms: endothelial (eNOS), neural (nNOS), and inducible (iNOS). Vascular tone regulation is primarily dependent on $\mathrm{NO}$ produced in the reaction catalyzed by eNOS [21,22]. Its production is regulated either at the level of its activity (increased by agonists such as $\mathrm{CO}$, bradykinin, acetylcholine, substance $\mathrm{P}$, thrombin, insulin, and shear stress) or gene expression [6,21-25]. NO stimulates the soluble receptor with guanylate cyclase activity (sGC) in a neighboring cell. This leads to an increase in the cyclic guanosine monophosphate (cGMP) concentration, and consequently to vasodilation (Figure 5). Another possible way to affect the NO-cGMP pathway is to modulate the activity or gene expression of sGC. Some substances activate the sGC [21,22].

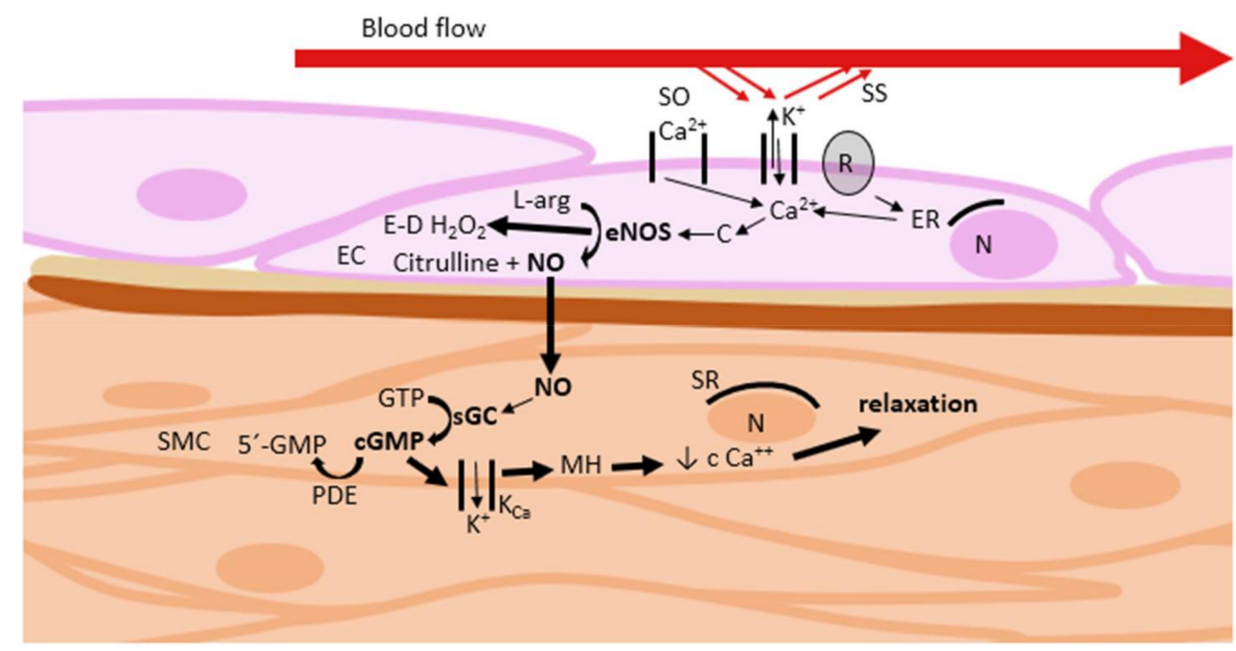

Figure 5. Regulation of vascular tone via nitric oxide-cyclic guanosine monophosphate pathway. C: calmodulin; cGMP: cyclic guanosine monophosphate; EC: endothelial cell; E- $\mathrm{D} \mathrm{H}_{2} \mathrm{O}_{2}$ : endotheliumderived $\mathrm{H}_{2} \mathrm{O}_{2}$; eNOS: endothelial NO synthase; ER: endoplasmic reticulum; GTP: guanosine triphosphate; $\mathrm{K}_{\mathrm{Ca}}$ : $\mathrm{Ca}^{2+}$-activated $\mathrm{K}^{+}$channels; L-arg: L-arginine; $\mathrm{MH}$ : membrane hyperpolarization; $\mathrm{N}$ : nucleus; NO: nitric oxide; PDE: phosphodiesterase; R: receptor; sGC: soluble receptor with guanylate cyclase activity; SMC: smooth muscle cell; $\mathrm{SO} \mathrm{Ca}^{2+}$ : store-operated $\mathrm{Ca}^{2+}$ channels; SR: sarcoplasmic reticulum; SS: shear stress. 
Inhibitors of both eNOS and sGC are used in studies focusing on the NO-cGMP pathway. In the case of eNOS, NG-nitro-L-arginine methyl esters or NG-monomethyl-L-arginine are most often used; in the case of sGC, methylene blue or $1 H$-[1,2,4]oxadiazole[4,3-a]quinoxalin1-one can be employed [21,22]. Another possible approach is the use of NO scavengers, e.g., hydroxocobalamin [26]. The plants are summarized in Table 1, the vasodilation effects of which are mediated via the NO-cGMP pathway. As examples, Cynara scolymus L. [27], Panax ginseng C. A. Meyer [28], and Theobroma cacao L. [29] can be mentioned.

Prostacyclin-Cyclic Adenosine Monophosphate Activation Pathway

Prostacyclin is an endogenous eicosanoid that relaxes vascular smooth muscle by stimulating the G-protein-coupled receptor. It is a vasodilator and platelet aggregation inhibitor, which activates adenylyl cyclase (AC), thereby increasing cyclic adenosine monophosphate (cAMP) levels. It also counterbalances the vasoconstrictor effect of thromboxane $\mathrm{A}_{2}$ $\left(\mathrm{TXA}_{2}\right)$. Arachidonic acid (ARA) is metabolized by cyclooxygenase (COX) to form unstable prostaglandin $\mathrm{H}_{2}\left(\mathrm{PGH}_{2}\right)$. PGI 2 release is further catalyzed by PGIS (Figure 6) [30-32]. Production of $\mathrm{PGI}_{2}$ is activated by endogenous substances, such as histamine, serotonin, bradykinin, and acetylcholine [32,33]. PGIS is activated by thrombin, cytokines, growth factors, and shear stress [31]. On the contrary, increased concentration of ROS inhibits PGIS activity, resulting in decreased $\mathrm{PGI}_{2}$ synthesis [30-32].

Numerous natural substances have been studied for their vasodilation effects mediated via the PGI2-cAMP pathway. Both AC inhibitor SQ22536 and protein kinase A inhibitor KT5720 can be employed to study this pathway. Another possibility is the use of analogues and antagonists of cyclic nucleotides or COX inhibitor indomethacin $[26,32,33]$. The plants' vasodilation effects, which are mediated via the PGI2-cAMP pathway, are summarized in Table 2. A frequently mentioned representative of this group is Piper truncatum Vell [34,35].

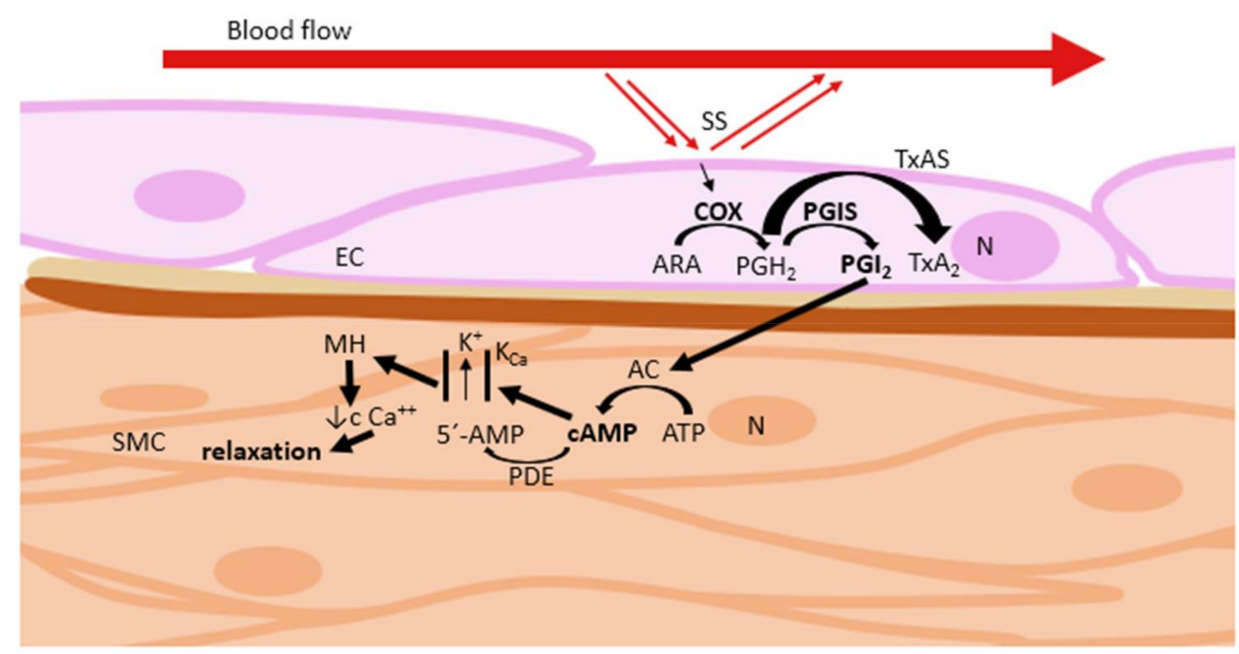

Figure 6. Regulation of vascular tone via prostacyclin-cyclic adenosine monophosphate pathway. AC: adenylyl cyclase; ARA: arachidonic acid; ATP: adenosine triphosphate; cAMP: cyclic adenosine monophosphate; COX: cyclooxygenase; EC: endothelial cell; $\mathrm{K}_{\mathrm{Ca}}$ : $\mathrm{Ca}^{2+}$-activated $\mathrm{K}^{+}$channels; $\mathrm{MH}$ : membrane hyperpolarization; $\mathrm{N}$ : nucleus; PDE: phosphodiesterase; $\mathrm{PGH}_{2}$ : prostaglandin $\mathrm{H}_{2}$; $\mathrm{PGI}_{2}$ : prostacyclin; PGIS: prostacyclin synthase; SMC: smooth muscle cell; SS: shear stress; TxAS: thromboxane synthase.

\section{Inhibition of Phosphodiesterase}

Cyclic nucleotide phosphodiesterases (PDEs) are enzymes regulating cellular cAMP and cGMP levels by regulation of their degradation rate. Inhibition of the PDE enzyme leads to an increase of cyclic nucleotide levels and induces vasodilation (Figure 7). The change in PDE activity, as measured by radioenzymatic assays, can elucidate the role of 
PDEs in the vasodilation effects of compounds in this pathway [33]. The plant metabolites that cause vasodilation via inhibition of PDE are summarized in Table 3. A model representative of such plants is Epimedium L. [36,37].

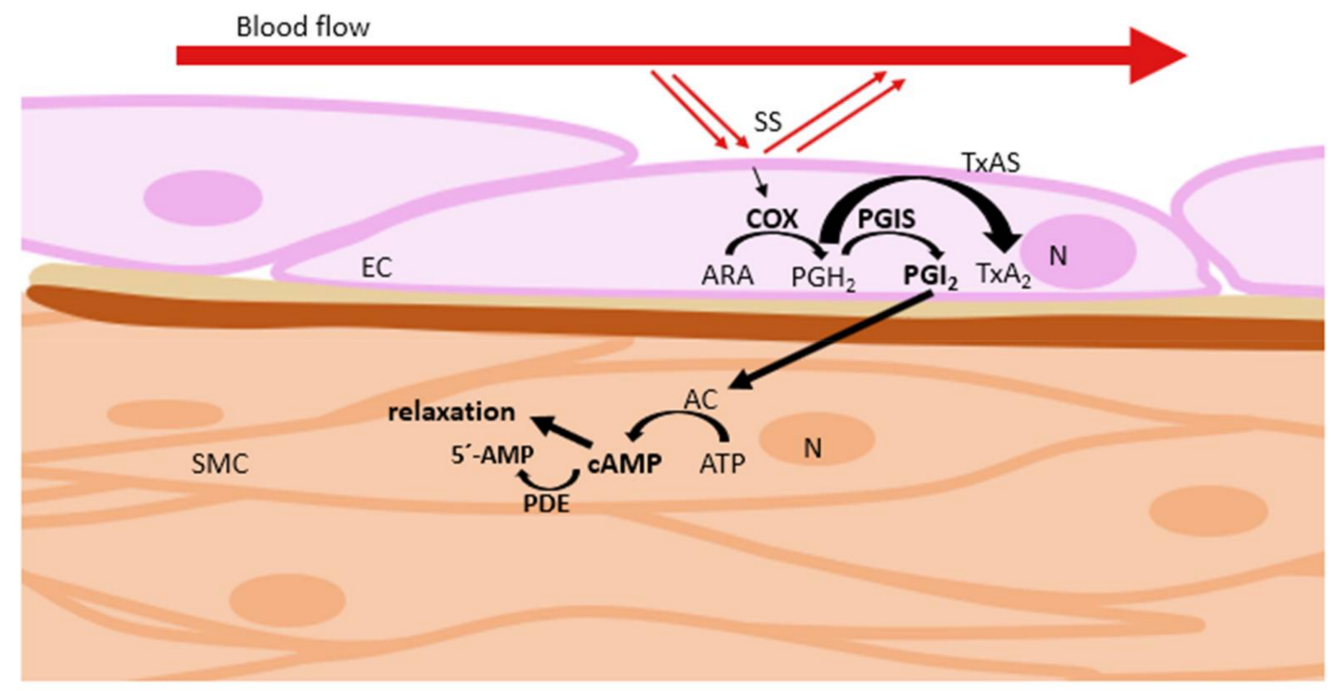

Figure 7. Regulation of vascular tone via inhibition of phosphodiesterase. AC: adenylyl cyclase; ARA: arachidonic acid; ATP: adenosine triphosphate; cAMP: cyclic adenosine monophosphate; COX: cyclooxygenase; EC: endothelial cell; $\mathrm{N}$ : nucleus; PDE: phosphodiesterase; $\mathrm{PGH}_{2}$ : prostaglandin $\mathrm{H}_{2}$; $\mathrm{PGI}_{2}$ : prostacyclin; PGIS: prostacyclin synthase; SMC: smooth muscle cell; SS: shear stress.

Activation of $\mathrm{K}^{+}$Channels or Inhibition of Intracellular $\mathrm{Ca}^{2+}$ Levels

Vascular smooth muscle cell (VSMC) relaxation can be directly regulated by specific ionic channels. An important role is played by $\mathrm{K}^{+}$channels. In VSMC, four different types of $\mathrm{K}^{+}$channels were characterized: voltage-dependent, $\mathrm{Ca}^{2+}$-activated, ATP-dependent, and inward rectifier $[33,38]$.

$\mathrm{K}^{+}$channels control the membrane potential in VSMC, thereby determining the activity of voltage-dependent $\mathrm{Ca}^{2+}$ channels (VDCC). $\mathrm{A} \mathrm{K}^{+}$channel opening leads to membrane hyperpolarization (Figure 8), resulting in closing of VDCC and preventing $\mathrm{Ca}^{2+}$ influx. The concentration of cytosolic $\mathrm{Ca}^{2+}$ is reduced, which leads to VSMC relaxation and consequent vasodilation [39]. A significant number of natural vasodilators at least partially utilize the mechanism of $\mathrm{Ca}^{2+}$-activated $\mathrm{K}^{+}$channel activation [33,38].

Decreasing of the intracellular $\mathrm{Ca}^{2+}$ concentration is another possibility to induce vasodilation. $\mathrm{Ca}^{2+}$ enters cells through a receptor-operated $\mathrm{Ca}^{2+}$ channel (ROCC) or VDCC. Obstructing these channels or inhibition of $\mathrm{Ca}^{2+}$ release from intracellular stores lead to vasodilation [33].

Endothelium-derived hyperpolarization (EDH) represents a vasodilation system that is particularly important in small arteries, which are mostly dependent on $\mathrm{Ca}^{2+}$ influx during contraction. $\mathrm{EDH}$ is used to describe the endothelium-dependent relaxation that is non-NO and non-prostanoid in nature. This results in VSMC hyperpolarization via opening of $\mathrm{K}^{+}$-channels or activation of $\mathrm{Na}^{+}-\mathrm{K}^{+}$-ATPase [38,40]. 


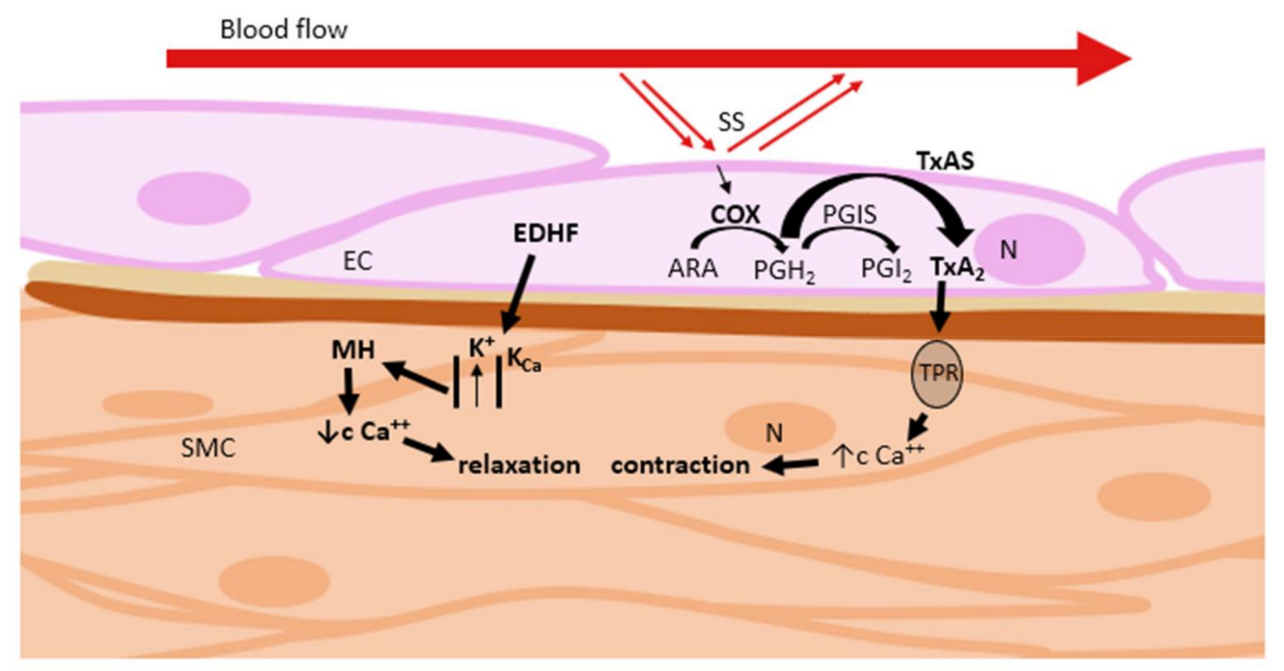

Figure 8. Regulation of vascular tone via activation of $\mathrm{K}^{+}$channels or inhibition of intracellular $\mathrm{Ca}^{2+}$ levels. ARA: arachidonic acid; ATP: adenosine triphosphate; cAMP: cyclic adenosine monophosphate; COX: cyclooxygenase; EC: endothelial cell; $\mathrm{K}_{\mathrm{Ca}}$ : $\mathrm{Ca}^{2+}$-activated $\mathrm{K}^{+}$channels; $\mathrm{MH}$ : membrane hyperpolarization; $\mathrm{N}$ : nucleus; $\mathrm{PGH}_{2}$ : prostaglandin $\mathrm{H}_{2} ; \mathrm{PGI}_{2}$ : prostacyclin; PGIS: prostacyclin synthase; SMC: smooth muscle cell; SS: shear stress; TPR: thromboxane $\mathrm{A}_{2}$-prostanoid receptor; TxAS: thromboxane synthase.

Since 1988, several candidates have been identified as the driver of EDH, including $\mathrm{H}_{2} \mathrm{O}_{2}$ [7], $\mathrm{H} 2 \mathrm{~S}$ [20,41,42], epoxyeicosatrienoic acids, metabolites of ARA, $\mathrm{K}^{+}$ions, electrical communication through gap junctions, and $\mathrm{P} 450$ epoxygenase pathway. Nowadays, E-D $\mathrm{H}_{2} \mathrm{O}_{2}$ is one of the major EDH in human vessels. It is generated by the dismutation of superoxide anions derived from various sources in the endothelium, including NADPH oxidase and eNOS [7]. Despite the fact that EDH evokes hyperpolarization and subsequent vasodilation (especially of small resistance vessels), higher concentrations of E-D $\mathrm{H}_{2} \mathrm{O}_{2}$ induce vasoconstriction by releasing COX-derived TXA 2 [7,43].

As mentioned above, although a lot of attention is paid to NO-targeted therapy and ROS elimination (including iACEs), the evidence indicates the importance of maintaining the delicate balance between NO and EDH. Moreover, despite the fact that ROS have been considered primarily harmful for cells and tissues, physiological levels of ROS can serve as crucial signaling molecules [7].

The vasodilation is caused by either $\mathrm{K}^{+}$channel activation or based on decreasing intracellular $\mathrm{Ca}^{2+}$ levels, which can be studied by using selective activators or blockers of specific ionic channels. Voltage-clamp or patch-clamp techniques help to elucidate the roles of particular channels and their activation or blocking in vasodilation processes. Another possibility is to study the vasodilation or vasoconstriction effect of a particular substance on isolated vessels or isolated aortic rings. Most of the present knowledge of the roles of ionic channels in vasodilation was gained in experiments using non-selective $\mathrm{K}^{+}$channel blockers chloride tetraethylammonium and $\mathrm{BaCl}_{2}$, ATP-dependent $\mathrm{K}^{+}$channel blocker glibenclamide, and voltage-dependent $\mathrm{K}^{+}$channel blocker 4-aminopyridine. Various compounds affecting either $\mathrm{Ca}^{2+}$ influx across the plasmatic membrane via $\mathrm{Ca}^{2+}$ channels (such as cobalt or verapamil) or its release or re-uptake from or to the sarcoplasmic reticulum (SR $\mathrm{Ca}^{2+}$ channel opener ryanodine or SR $\mathrm{Ca}^{2+}$-ATPase blockers cyclopiazonic acid and thapsigargin) can be used in studies focusing on the changes of cytosolic $\mathrm{Ca}^{2+}$ availability and its impact on vascular tone [33]. The plants and their primary or secondary metabolites that lead to vasodilation via this pathway are summarized in Table 4 .

All of the abovementioned substances are vasodilatory ones. Contrary to this, ET-1 and TXA 2 are endothelium-produced vasoconstrictors. Next to them, AT II-mediated vasoconstriction is worth mentioning [32]. 


\subsubsection{Other Endothelial Functions}

In addition to the previously described functions, other endothelium functions should be mentioned, such as its role in hemostasis and coagulation. Endothelial and smooth muscle cells express a variety of proteins that act both pro- and antithrombotically (intact non-wettable endothelium is an important factor in preventing intravascular hemocoagulation). Endothelial cells also participate in the regulation of inflammation [6,44].

Another endothelium function is the transport of numerous substances dissolved in blood to the subendothelial space to meet the metabolic needs of the surrounding tissues [6].

Finally, the endothelium participates in lipid metabolism on one side, while circulating lipids (fatty acids, lipoproteins) alter endothelial function on the other side. This leads to certain endothelial changes that exacerbate inflammatory processes and may promote certain diseases, such as atherogenesis [45].

\section{Substances Affecting Vascular Tone}

\subsection{Substances with Vasoconstriction Activity}

Most research is focused on substances with vasodilatory potential, since these are of high clinical relevance. Although there are also some substances with vasoconstriction activity, research studies focus on them quite rarely. In folk medicine, some plants are used for their vasoconstriction activity, e.g., Cissus sicyoides L. (Vitaceae Juss.) [46], Nicotiana tabacum L. (Solanaceae Juss.) [47,48], Potentilla erecta (L.) Räusch. (Rosaceae L.) [49], Paspalidium flavidum (Retz.) A. Camus (Poaceae Barnhart) [50], and Haloxylon recurvum Bunge ex Boiss. (Amaranthaceae Juss.) [51,52].

\subsubsection{Thromboxane $A_{2}$}

Thromboxane $\mathrm{A}_{2}$ (as well as $\mathrm{PGI}_{2}$ ) is a metabolite of ARA. For a long time, $\mathrm{TXA}_{2}$ was known to be released from platelets. Nowadays, it is known to be released by a variety of cells, including the endothelial ones. It stimulates platelet activation, aggregation, and proliferation, as well as vasoconstriction [53,54]. It counterbalances the effects of $\mathrm{PGI}_{2}$, especially in pathological situations, such as tissue injury and inflammation [54]. ARA is metabolised by COX to form unstable $\mathrm{PGH}_{2}$. $\mathrm{PGH}_{2}$ is further converted into $\mathrm{TXA}_{2}$ by thromboxane synthase (TXAS) [53]. TXA 2 binds to TXA $A_{2}$-prostanoid receptor (TPR), resulting in an influx of $\mathrm{Ca}^{2+}$ ions and VSMC contraction $[53,54]$. Production of $\mathrm{TXA}_{2}$ can be evoked by acetylcholine, among others. TX $\mathrm{A}_{2}$ level reduction and TPR antagonism may be promising therapeutic targets to prevent cardiovascular disease [53,55].

As mentioned above, the production of synergic $\mathrm{TXA}_{2}$ and $\mathrm{PGI}_{2}$ is catalyzed by $\mathrm{COX}$ enzymes. The two COX isoforms, cyclooxygenase 1 (COX-1) and cyclooxygenase 2 (COX2), metabolise ARA to $\mathrm{PGH}_{2}$, the common substrate for $\mathrm{TXA}_{2}$ and $\mathrm{PGI}_{2}$ synthesis. $\mathrm{TXA}_{2}$ is the predominant COX-1-derived product, in contrast to $\mathrm{PGI}_{2}$, which is synthetized as a result of COX-2 activation [32,56].

\subsubsection{Endothelin}

The common name endothelin (ET) is used for three peptides, namely endothelin-1, -2 , and -3 (ET-1, ET-2, and ET-3). ET-1 is the most examined endothelin and is considered the most potent vasoconstrictive substance to date. Its expression is stimulated by shear stress, thrombin, insulin, adrenaline, AT II, cortisol, and also by hypoxia; it is inhibited by $\mathrm{NO}$ and natriuretic peptides. ET-1 is produced by endothelial cells, smooth muscle cells, macrophages, fibroblasts, cardiomyocytes, neurons, and endocrine pancreas cells. ET- 2 is formed in the ovaries and intestinal epithelial cells. ET-3 is expressed in endothelial cells, placenta, brain neurons, melanocytes, and renal tubular epithelial cells [57-61].

Formation of the final, biologically active ET- 1 is catalyzed by endothelin-converting enzymes 1-3 (ECE 1-3), each occurring in several isoforms. ECE-1 is the major enzyme, which catalyzes all endothelin isoform formation. 
Endothelin receptors $\mathrm{ET}_{\mathrm{A}}, \mathrm{ET}_{\mathrm{B} 1}, \mathrm{ET}_{\mathrm{B} 2}$, and $\mathrm{ET}_{\mathrm{C}}$ are $\mathrm{G}$-protein-coupled receptors, differing in their affinity for individual ETs. ET-1 via $\mathrm{ET}_{\mathrm{A}}$ mediates vasoconstriction $\left(\mathrm{ET}_{\mathrm{A}}\right.$ is expressed mainly in smooth muscle cells). Moreover, bronchoconstriction and secretion of aldosterone are mediated via $\mathrm{ET}_{\mathrm{A}}$. $\mathrm{ET}_{\mathrm{B} 1}$ and $\mathrm{ET}_{\mathrm{B} 2}$ occur in both endothelial and smooth muscle cells. $\mathrm{ET}_{\mathrm{B} 1}$ agonist causes vasodilation by stimulating $\mathrm{NO}, \mathrm{PGI}_{2}$, and $\mathrm{EDH}$. On the contrary, $\mathrm{ET}_{\mathrm{B} 2}$ mediates vasoconstriction [57-61].

\subsubsection{Platelet-Activating Factor}

Platelet-activating factor (PAF) is a phospholipid mediator, synthesis and degradation of which are catalyzed enzymatically. PAF plays a role in numerous pathophysiological reactions-it potentiates aggregation and chemotaxis, as well as formation of neutrophils, eosinophils, and monocytes. In other words, by increasing vascular permeability, it induces local inflammatory processes and edema [62].

\section{Exogenous Substances with Vasodilation Activity}

Endogenous substances with vasodilatory potential were overviewed in previous chapters. This chapter is focused on plants with a potential vasodilating effect. Table 1 to Table 4 summarize plants and their primary or secondary metabolites, in which certain effects dominate a particular signaling pathway-in Table 1 it is the NO-cGMP activation pathway, in Table 2 it is the PGI2-cAMP activation pathway, in Table 3 it is inhibition of $\mathrm{PDE}$, and in Table 4 it is activation of $\mathrm{K}^{+}$channels or inhibition of intracellular $\mathrm{Ca}^{2+}$ levels.

Numerous plants exhibiting vasodilatory effects are reported to use more than one signaling pathway. In Table 5, plant metabolites with combined mechanisms and without a dominant mechanism are summarized. Table 6 presents the plant metabolites, the effects of which have not yet been fully elucidated. Most metabolites with vasodilatory activity belong to alkaloids, flavonoids, or terpenes; additionally, stilbenes, lignans, xanthones, and coumarins are reported to have vasoactive effects. Numerous studies suggest that the most common mechanisms are interactions with the NO-cGMP pathway [33].

Table 1. Nitric oxide-cyclic guanosine monophosphate activation pathway.

\begin{tabular}{|c|c|c|c|}
\hline Plant(s) & Primary/Secondary Metabolite(s) & Plant Part(s) Used & Citation(s) \\
\hline $\begin{array}{l}\text { Allium sativum } \mathrm{L} . \\
\text { (Amaryllidaceaee Jaume } \\
\text { St.-Hil.) }\end{array}$ & alliin, allicin & aged garlic extract & [63-66] \\
\hline $\begin{array}{c}\text { Alpinia purpurata (Vieill.) K. Schum. } \\
\text { (Zingiberaceae Lindl.) }\end{array}$ & $\begin{array}{c}\text { rutin, quercetin, } \\
\text { kaempferol-3-O- } \beta \text {-D-glucuronide }\end{array}$ & leaves & [67] \\
\hline $\begin{array}{c}\text { Alpinia zerumbet (Pers.) Burtt \& R.M. Sm. } \\
\text { (Zingiberaceae Lindl.) }\end{array}$ & $\begin{array}{l}\text { catechin, epicatechin, rutin, quercetin, } \\
\text { kaempferol 3-O-rutinoside, } \\
\text { kaempferol 3-O-glucuronide, } \\
\text { dihydro-5,6-dehydrokawain, } \\
\text { 5,6-dehydrokawain }\end{array}$ & leaves & {$[67,68]$} \\
\hline $\begin{array}{l}\text { Arbutus unedo L. } \\
\quad \text { (Ericaceae) }\end{array}$ & $\begin{array}{l}\text { tannins, afzeline, juglamine, } \\
\text { avicularine, quercitroside, hyperoside }\end{array}$ & leaves, roots & {$[69]$} \\
\hline $\begin{array}{l}\text { Caesalpinia sappan L. } \\
\text { (Fabaceae Lindl.) }\end{array}$ & brazilin and hematoxylin & heartwood & {$[70,71]$} \\
\hline $\begin{array}{l}\text { Calicotome villosa (Poir.) Link. } \\
\text { (Fabaceae Lindl.) }\end{array}$ & chrysin & flowers, leaves & [72-74] \\
\hline $\begin{array}{l}\text { Canavalia DC. } \\
\text { (Fabaceae Lindl.) }\end{array}$ & lectins & seeds & {$[75,76]$} \\
\hline $\begin{array}{c}\text { Casimiroa Llave \& Lex (Casimirova edulis } \\
\text { Llave \& Lex and Casimiroa pubescens Ramírez) } \\
\text { (Rutaceae Juss.) }\end{array}$ & $\begin{array}{c}\text { hernianin, imperatorin, } \\
\text { geranyloxypsoralen } \\
5,6,2^{\prime}, 3^{\prime}, 4^{\prime} \text {-pentamethoxyflavon }\end{array}$ & seeds, leaves & {$[77,78]$} \\
\hline
\end{tabular}


Table 1. Cont.

\begin{tabular}{|c|c|c|c|}
\hline Plant(s) & Primary/Secondary Metabolite(s) & Plant Part(s) Used & Citation(s) \\
\hline $\begin{array}{c}\text { Centaurium cachanlahuen (Mol.) Robinson } \\
\text { (Gentianaceae Juss.) }\end{array}$ & xanthones & stems, flowers, leaves & [79] \\
\hline $\begin{array}{l}\text { Cistus ladaniferus L. } \\
\text { (Cistaceae Juss.) }\end{array}$ & quercetin, kaempferol, myricetin & leaves & {$[80]$} \\
\hline $\begin{array}{l}\text { Coptosapelta flavescens Korth } \\
\text { (Rubiaceae Juss.) }\end{array}$ & saponin, polyphenols & stems & [81] \\
\hline $\begin{array}{l}\text { Crithmum maritimum L. } \\
\text { (Apiaceae Lindl.) }\end{array}$ & $\begin{array}{l}\text { limonene, terpinen-4-ol, carvacrol, } \\
\text { thymol, chlorogenic acid }\end{array}$ & flowers, stems, leaves & [82] \\
\hline $\begin{array}{l}\text { Croton schiedeanus Schlecht } \\
\quad \text { (Euphorbiaceae Juss.) }\end{array}$ & $\begin{array}{l}\text { quercetin 3,7-dimethyl ether, } \\
\text { diterpenoid and fenylbutanoid } \\
\text { compounds }\end{array}$ & aerial parts & [83-85] \\
\hline $\begin{array}{c}\text { Cynara scolymus L. } \\
\text { (Asteraceae Martinov) }\end{array}$ & $\begin{array}{l}\text { cymaroside, luteolin, cynarin, } \\
\text { chlorogenic acid }\end{array}$ & leaves & [27] \\
\hline $\begin{array}{c}\text { Derris (Lonchocarpus) urucu Killip \& A. C. } \\
\text { Smith } \\
\text { (Fabaceae Lindl.) }\end{array}$ & isotirumalin & leaves & {$[86,87]$} \\
\hline $\begin{array}{l}\text { Euterpe oleracea C. Martius } \\
\text { (Arecaceae Bercht \& J. Presl) }\end{array}$ & $\begin{array}{c}\text { cyanidin 3-O-arabinoside, cyanidin } \\
\text { 3-O-glucoside, cyanidin } \\
\text { 3-O-rutinoside, epicatechine, } \\
\text { catechine homorientin, orientin, } \\
\text { isovitexin, taxifolin deoxyhexose }\end{array}$ & fruits & [88] \\
\hline $\begin{array}{l}\text { Geum japonicum Thunberg } \\
\text { (Rosaceae L.) }\end{array}$ & $\begin{array}{l}\text { penta-O-galloyl- } \beta \text {-glucoside, } \\
\text { casuariin, and 5-desgalloylstachyurin }\end{array}$ & whole plants & [89] \\
\hline $\begin{array}{l}\text { Ginkgo biloba L. } \\
\text { (Ginkgoaceae) }\end{array}$ & bilobalide & leaves & {$[90,91]$} \\
\hline $\begin{array}{c}\text { Inula viscosa } \mathrm{L} . \\
\text { (Asteraceae Martinov) }\end{array}$ & cynarin, chlorogenic acid & leaves & [92] \\
\hline $\begin{array}{l}\text { Magnolia grandiflora L. } \\
\text { (Magnoliaceae Juss.) }\end{array}$ & vulgarenol & flower petals & [93] \\
\hline $\begin{array}{l}\text { Microdesmis keayana J. Léonard } \\
\text { (Pandanaceae) }\end{array}$ & keayanidin B, keayanin & roots & [94] \\
\hline $\begin{array}{l}\text { Ocimum gratissimum } \mathrm{L} . \\
\text { (Lamiaceae Lindl.) }\end{array}$ & eugenol & leaves & {$[95,96]$} \\
\hline $\begin{array}{l}\text { Paeonia sect. Moutan DC. } \\
\text { (Paeoniaceae) }\end{array}$ & $\begin{array}{l}\text { paeoniflorin, paeonidanin, } \\
\text { methylpaeoniflorin, } \\
\text { tetragalloylglucose, } \\
\text { pentagalloylglucose }\end{array}$ & rootbark & {$[97]$} \\
\hline $\begin{array}{c}\text { Panax ginseng C. A. Meyer } \\
\text { (Araliaceae Juss.) }\end{array}$ & ginsenoside-Rg1, ginsenoside Rb1 & roots & {$[28,98,99]$} \\
\hline $\begin{array}{l}\text { Prunella vulgaris L. } \\
\text { (Lamiaceae Lindl.) }\end{array}$ & $\begin{array}{c}\text { cynaroside, luteolin, ursolic acid, } \\
\text { betulinic acid, quercetin }\end{array}$ & flowering spike & {$[100,101]$} \\
\hline $\begin{array}{l}\text { Raphanus sativus L. } \\
\text { (Brassicaceae Burnett) }\end{array}$ & $\begin{array}{l}\text { sinapine thiocyanate, glucosinolates, } \\
\text { brassinosteroids, flavonoids }\end{array}$ & seeds, leaves & {$[102,103]$} \\
\hline $\begin{array}{l}\text { Rheum undulatum L. } \\
\text { (Polygonaceae Juss.) }\end{array}$ & $\begin{array}{l}\text { piceatannol, tetrahydroxystilbene, } \\
\text { resveratrol, anthraquinone derivates }\end{array}$ & rhizomes & {$[104-106]$} \\
\hline $\begin{array}{c}\text { Saururus chinensis (SC) Baill. } \\
\text { (Saururaceae) }\end{array}$ & saucerneol, saucerneol D, machilin D & roots & {$[107]$} \\
\hline
\end{tabular}


Table 1. Cont.

\begin{tabular}{|c|c|c|c|}
\hline Plant(s) & Primary/Secondary Metabolite(s) & Plant Part(s) Used & Citation(s) \\
\hline $\begin{array}{c}\text { Selaginella tamariscina (Beauv.) Spring. } \\
\text { (Selaginellaceae) }\end{array}$ & amentoflavone & whole plants & {$[108,109]$} \\
\hline $\begin{array}{l}\text { Solanum crispum Ruiz \& Pav } \\
\text { (Solanaceae Juss.) }\end{array}$ & $\begin{array}{l}\text { alkaloids, flavonoids, resins, } \\
\text { saponins, tannins }\end{array}$ & stems, leaves & [110] \\
\hline $\begin{array}{l}\text { Tabernaemontana dichotoma Roxb. ex Wall. } \\
\text { (Apocynaceae Juss.) }\end{array}$ & $\begin{array}{l}\text { 10-methoxyaffinisine, cathafoline, } \\
\text { alstonisine }\end{array}$ & bark & [111] \\
\hline $\begin{array}{l}\text { Tapirira guianensis Aubl. } \\
\text { (Anacardiaceae Lindl.) }\end{array}$ & $\begin{array}{c}\text { triterpenoids, quercetin, myricetin } \\
\text { glycoside, hyperoside, } \\
\text { penta-O-galloyl- } \beta \text {-glucoside }\end{array}$ & leaves & [112] \\
\hline $\begin{array}{l}\text { Theobroma cacao L. } \\
\text { (Malvaceae Juss.) }\end{array}$ & epicatechin, oligomeric procyanidins & seeds & $\begin{array}{l}{[29,113-} \\
116]\end{array}$ \\
\hline $\begin{array}{l}\text { Vitis labrusca L. } \\
\text { (Vitaceae Juss.) }\end{array}$ & $\begin{array}{l}\text { vitisin } \mathrm{C} \text {, phenolic acids, } \\
\text { anthocyanins, flavonoids }\end{array}$ & grape skin, stems & [117-119] \\
\hline $\begin{array}{l}\text { Vitis vinifera } \mathrm{L} . \\
\text { (Vitaceae Juss.) }\end{array}$ & $\begin{array}{l}\text { vitisin } \mathrm{C} \text {, phenolic acids, } \\
\text { anthocyanins, flavonoids }\end{array}$ & grape skin, stems & $\begin{array}{l}{[117,119-} \\
122]\end{array}$ \\
\hline $\begin{array}{l}\text { Ziziphus jujuba (L.) Mill. } \\
\text { (Rhamnaceae Juss.) }\end{array}$ & betulinic acid & seeds & [123] \\
\hline
\end{tabular}

Table 2. Prostacyclin-cyclic adenosine monophosphate activation pathway.

\begin{tabular}{cccc}
\hline Plant(s) & Primary/Secondary Metabolite(s) & Plant Part(s) Used & Citation(s) \\
\hline $\begin{array}{c}\text { Kaempferia galanga L. } \\
\text { (Zingiberaceae Lindl.) }\end{array}$ & ethyl cinnamate & rhizomes & [124] \\
\hline $\begin{array}{c}\text { Piper truncatum Vell. } \\
\text { (Piperaceae C. A. Agardh) }\end{array}$ & eudesmin & leaves, stems & {$[34,35]$} \\
\hline $\begin{array}{c}\text { Xylopia langdorffiana A.St.-Hil. \& Tul. } \\
\text { (Annonaceae Juss.) }\end{array}$ & labdane-302 & stems & {$[125,126]$} \\
\hline
\end{tabular}

Table 3. Inhibition of phosphodiesterase.

\begin{tabular}{cccc}
\hline Plant(s) & Primary/Secondary Metabolite(s) & Plant Part(s) Used & Citation(s) \\
\hline $\begin{array}{c}\text { Coffea arabica } \text { L. } \\
\text { (Rubiaceae Juss.) }\end{array}$ & $\begin{array}{c}\text { caffeine, theobromine, theophylline, chlorogenic } \\
\text { acid, quercetin, ferulic acid, kaempferol, rutin }\end{array}$ & seeds & {$[127-129]$} \\
\hline $\begin{array}{c}\text { Epimedium } \text { L. } \\
\text { (Berberidaceae Juss.) }\end{array}$ & icariin & young stems & {$[36,37,130-132]$} \\
\hline
\end{tabular}

Table 4. Activation of $\mathrm{K}^{+}$channels or inhibition of intracellular $\mathrm{Ca}^{2+}$ levels.

\begin{tabular}{|c|c|c|c|}
\hline Plant(s) & Primary/Secondary Metabolite(s) & Plant Part(s) Used & Citation(s) \\
\hline $\begin{array}{l}\text { Alchemilla vulgaris L. } \\
\quad \text { (Rosaceae L.) }\end{array}$ & quercetin & aerial parts & {$[133,134]$} \\
\hline $\begin{array}{l}\text { Ammi visnaga (L.) Lam. } \\
\text { (Apiaceae Lindl.) }\end{array}$ & visnagin & fruits & [135] \\
\hline $\begin{array}{l}\text { Calea glomerata Klatt. } \\
\text { (Asteraceae Martinov) }\end{array}$ & flavonoids, terpenoids & aerial parts & {$[83,136]$} \\
\hline $\begin{array}{c}\text { Cistus populifolius L. } \\
\text { (Cistaceae Juss.) }\end{array}$ & diterpenoids, luteolin & leaves & {$[137,138]$} \\
\hline $\begin{array}{c}\text { Cymbopogon martini (Roxb.) W.Watson } \\
\text { (Poaceae Barnhart) }\end{array}$ & geraniol & leaves & [139] \\
\hline
\end{tabular}


Table 4. Cont.

\begin{tabular}{|c|c|c|c|}
\hline Plant(s) & Primary/Secondary Metabolite(s) & Plant Part(s) Used & Citation(s) \\
\hline $\begin{array}{l}\text { Garcinia kola Heckel } \\
\text { (Guttiferae Juss.) }\end{array}$ & kolaviron & seeds & [140] \\
\hline $\begin{array}{c}\text { Gentiana kochiana J.O.E. Perrier \& Songeon } \\
\text { (Gentianaceae Juss.) }\end{array}$ & gentiacaulein, gentiakochianin & roots & [141] \\
\hline $\begin{array}{l}\text { Halenia elliptica D. Don } \\
\text { (Gentianaceae Juss.) }\end{array}$ & $\begin{array}{l}\text { 1-hydroxy-2,3,5-trimethoxy-xanthone } \\
\text { (HM-1) }\end{array}$ & whole plants & [142] \\
\hline $\begin{array}{l}\text { Hibiscus sabdariffa L. } \\
\text { (Malvaceae Juss.) }\end{array}$ & hibiscus acid, garcinia acid & calyces & [143] \\
\hline $\begin{array}{c}\text { Iostephane heterophylla (Cav.) Benth. } \\
\text { (Asteraceae Martinov) }\end{array}$ & xanthorrhizol & whole plants & [144] \\
\hline $\begin{array}{c}\text { Ligusticum jeholense Nakai et Kitagawa } \\
\text { (Apiaceae Lindl.) }\end{array}$ & linoleic acid, ferulic acid, ligustilide & roots, rhizomes & [145] \\
\hline $\begin{array}{l}\text { Marrubium vulgare L. } \\
\text { (Lamiaceae Lindl.) }\end{array}$ & marrubiin, marrubenol & aerial parts & {$[146,147]$} \\
\hline $\begin{array}{l}\text { Maxillaria densa Lindl. } \\
\text { (Orchidaceae Juss.) }\end{array}$ & gymnopusin, fimbriol A, erianthridin & whole plants & [148] \\
\hline $\begin{array}{l}\text { Morinda citrifolia L. } \\
\text { (Rubiaceae Juss.) }\end{array}$ & $\begin{array}{l}\text { alkaloid xeronine, phenolic compounds, } \\
\text { sterols, flavonoids, tannins, coumarins, } \\
\text { anthraquinones }\end{array}$ & roots & {$[149,150]$} \\
\hline $\begin{array}{c}\text { Nauclea officinalis (Pierre ex Pit.) } \\
\text { Merr. \& Chun } \\
\text { (Rubiaceae Juss.) }\end{array}$ & $\begin{array}{l}\text { naucline, angustine, nauclefine, } \\
\text { naucletine }\end{array}$ & bark & {$[151,152]$} \\
\hline $\begin{array}{l}\text { Peganum harmala L. } \\
\text { (Zygophyllaceae) }\end{array}$ & harmaline, harmine, harmalol & seeds & [153-155] \\
\hline $\begin{array}{c}\text { Polygala caudata Rehder \& E.H.Wilson } \\
\text { (Polygalaceae Juss.) }\end{array}$ & euxanthone & roots & {$[156,157]$} \\
\hline $\begin{array}{c}\text { Prunus yedoensis Matsum } \\
\text { (Rosaceae L.) }\end{array}$ & prunetin & bark & {$[158,159]$} \\
\hline $\begin{array}{l}\text { Sarcococca saligna (D. Don) Muell.-Arg. } \\
\text { (Buxaceae Dumort.) }\end{array}$ & flavonoids & whole plants & [160] \\
\hline $\begin{array}{c}\text { Trachyspermum ammi (L.) Sprague } \\
\text { (Apiaceae Lindl.) }\end{array}$ & $\begin{array}{l}\text { thymol, gamma-terpinene, } \\
\text { p-cymene }\end{array}$ & seeds & [161] \\
\hline $\begin{array}{l}\text { Uncaria rhynchophylla (Miquel) Jack } \\
\text { (Rubiaceae Juss.) }\end{array}$ & $\begin{array}{c}\text { rhynchophylline, isorhynchophylline, } \\
\text { hirsutine }\end{array}$ & hooks & {$[162,163]$} \\
\hline
\end{tabular}

Table 5. Combination of mechanisms without a dominant one.

\begin{tabular}{|c|c|c|c|}
\hline Plant(s) & Primary/Secondary Metabolite(s) & Plant Part(s) Used & Citation(s) \\
\hline $\begin{array}{c}\text { Agastache Mexicana (Kunth.) Link. \& } \\
\text { Epling } \\
\text { (Lamiaceae Lindl.) }\end{array}$ & tilianin, acecatin & aerial parts & {$[164,165]$} \\
\hline $\begin{array}{c}\text { Alpinia henryi K. Schum. } \\
\text { (Zingiberaceae Lindl.) }\end{array}$ & cardamonin, alpinetin & seeds & {$[166,167]$} \\
\hline $\begin{array}{l}\text { Alstonia scholaris (L.) R. Br. } \\
\quad \text { (Apocynaceae Juss.) }\end{array}$ & $\begin{array}{c}\text { picrinine, schloaricine, alstonamine, } \\
\text { rhazimanine, botulin, ursolic acid, } \\
\beta \text {-sitosterol }\end{array}$ & bark, leaves & {$[168,169]$} \\
\hline $\begin{array}{c}\text { Alstonia macrophylla Wall. ex G. Don } \\
\text { (Apocynaceae Juss.) }\end{array}$ & vincamedine & leaves & [170] \\
\hline
\end{tabular}


Table 5. Cont.

\begin{tabular}{|c|c|c|c|}
\hline Plant(s) & Primary/Secondary Metabolite(s) & Plant Part(s) Used & Citation(s) \\
\hline $\begin{array}{c}\text { Andrographis paniculata (burm. F.) Nees } \\
\text { (Acanthaceae Juss.) }\end{array}$ & $\begin{array}{c}\text { 14-deoxyandrographolide, } \\
\text { 14-deoxy-11,12-dihydroandrographolide }\end{array}$ & leaves & {$[171-174]$} \\
\hline $\begin{array}{l}\text { Angelica dahurica Benthman et Hooker } \\
\text { (Apiaceae Lindl.) }\end{array}$ & $\begin{array}{c}\text { pyranocoumarin, biscoumarin, } \\
\text { isoimperatorin, imperatorin, phellopterin, } \\
\text { isodemethylfuropinarine, } \\
\text { demethylfuropinarine, decursinol }\end{array}$ & roots, rhizomes & [175-178] \\
\hline $\begin{array}{l}\text { Angelica gigas Nakai } \\
\text { (Apiaceae Lindl.) }\end{array}$ & ferulic acid & roots & [179] \\
\hline $\begin{array}{l}\text { Angelica keiskei Koidz. } \\
\quad \text { (Apiaceae Lindl.) }\end{array}$ & $\begin{array}{c}\text { xanthoangelol, } \\
\text { 4-hydroxyderricin, xanthoangelol B, } \\
\text { xanthoangelol E, xanthoangelol F }\end{array}$ & roots & [180] \\
\hline $\begin{array}{c}\text { Apium graveolens L. var. dulce DC } \\
\text { (Apiaceae Lindl.) }\end{array}$ & apigenin & leaves, roots & [181-183] \\
\hline $\begin{array}{c}\text { Bacopa monnieri (L.) Pennel } \\
\text { (Plantaginaceae Juss.) }\end{array}$ & bacoside A, bacopaside I, luteolin, apigenin & whole plants & [184-187] \\
\hline $\begin{array}{l}\text { Berberis vulgaris L. } \\
\text { (Berberidaceae Juss.) }\end{array}$ & berberine & fruits, stems bark, roots & {$[188,189]$} \\
\hline $\begin{array}{l}\text { Camellia sinensis (L.) Kunzte } \\
\quad \text { (Theaceae D. Don) }\end{array}$ & $\begin{array}{l}\text { epigallocatechin-3-gallate, epicatechin, } \\
\text { epigallocatechin, epicatechin-3-gallate }\end{array}$ & green tea (leaves) & [190-194] \\
\hline $\begin{array}{l}\text { Chenopodium ambrosioides } \\
\text { L.(Amaranthaceae Juss.) }\end{array}$ & $\begin{array}{l}\text { kaempferol, quercetin, isorhamnetin, } \\
\text { catechins, delphinidin }\end{array}$ & leaves & [195] \\
\hline $\begin{array}{c}\text { Chrysanthemum morifolium Ramat } \\
\text { (Asteraceae Martinov) }\end{array}$ & $\begin{array}{l}\text { luteolin-7-O- } \beta \text {-D-glucoside, } \\
\text { apigenin-7- } O-\beta \text {-D-glucoside, } \\
\text { acacetin-7- } O-\beta \text {-D-glucoside }\end{array}$ & flowers & [196] \\
\hline $\begin{array}{l}\text { Coptis chinensis Franch. } \\
\text { (Ranunculaceae Arnott) }\end{array}$ & berberine, coptisine & rhizomes & [197-200] \\
\hline $\begin{array}{c}\text { Curcuma longa L. } \\
\text { (Zingiberaceae Lindl.) }\end{array}$ & $\begin{array}{c}\text { curcumane C, curcumane D, } \\
\text { 4,5-seco-cadinane sesquiterpenoid }\end{array}$ & rhizomes & [201] \\
\hline $\begin{array}{l}\text { Dalbergia odorifera T. Chen } \\
\text { (Fabaceae Lindl.) }\end{array}$ & butein, isoliquiritigenin, biochanin A & roots, leaves & [202-208] \\
\hline $\begin{array}{l}\text { Dioclea grandiflora Mart. ex Benth } \\
\text { (Fabaceae Lindl.) }\end{array}$ & dioclein, floranol & roots & [209-213] \\
\hline $\begin{array}{c}\text { Echinodorus grandiflorus (Cham. \& } \\
\text { Schltdl.) Micheli) } \\
\text { (Alismataceae Vent.) }\end{array}$ & flavonoids, diterpenes, triterpenes & leaves & [214-216] \\
\hline $\begin{array}{l}\text { Elsholtzia splendens Nakai } \\
\text { (Lamiaceae Lindl.) }\end{array}$ & apigenin, luteolin & aerial parts & {$[217,218]$} \\
\hline $\begin{array}{c}\text { Hancornia speciosa B. A. Gomes } \\
\text { (Apocynaceae Juss.) }\end{array}$ & rutin & leaves & [219] \\
\hline $\begin{array}{l}\text { Liqusticum wallichii Franchat } \\
\text { (Apiaceae Lindl.) }\end{array}$ & $\begin{array}{l}\text { butylidenephthalide, ligustilide, } \\
\text { senkyunolide A, tetramethylpyrazine }\end{array}$ & rhizomes & [220-223] \\
\hline $\begin{array}{l}\text { Mentha X villosa Hudson } \\
\text { (Lamiaceae Lindl.) }\end{array}$ & rotundifolone & leaves & [224-227] \\
\hline $\begin{array}{l}\text { Mitragyna ciliata aubrev. \& } \\
\text { Pellegr.(Rubiaceae Juss.) }\end{array}$ & $\begin{array}{l}\text { mitragynine, mitraphylline, rhynophylline, } \\
\text { flavonoids }\end{array}$ & stem bark & [228] \\
\hline $\begin{array}{l}\text { Phaeanthus crassipetalus Becc. } \\
\text { (Annonaceae Juss.) }\end{array}$ & limacine, pecrassipine $\mathrm{A}$, backebergine & bark, leaves & [229] \\
\hline
\end{tabular}


Table 5. Cont.

\begin{tabular}{|c|c|c|c|}
\hline Plant(s) & Primary/Secondary Metabolite(s) & Plant Part(s) Used & Citation(s) \\
\hline $\begin{array}{l}\text { Picrorhiza kurroa L. } \\
\text { (Plantaginaceae Juss.) }\end{array}$ & apocynin & roots & {$[230,231]$} \\
\hline $\begin{array}{l}\text { Prunus serotina Ehrh } \\
\text { (Rosaceae L.) }\end{array}$ & ursolic acid, uvaol & fruits & [232] \\
\hline $\begin{array}{c}\text { Schisandra chinensis (Turcz.) Baill. } \\
\text { (Schisandraceae Bl.) }\end{array}$ & schizandrin, $\gamma$-schizandrin, gomisin A & fruits (seeds) & [233-235] \\
\hline $\begin{array}{l}\text { Scutellaria baicalensis Georgi } \\
\text { (Lamiaceae Lindl.) }\end{array}$ & baicalin & roots & {$[236,237]$} \\
\hline $\begin{array}{l}\text { Senecio nutans Sch. Bip. } \\
\text { (Asteraceae Martinov) }\end{array}$ & $\begin{array}{l}\text { 4-hydroxy-3-(3-methyl-2- } \\
\text { butenyl)acetophenone, } \\
\text { 5-acetyl-6-hydroxy-2-isopropenyl-2,3- } \\
\text { dihydrobenzofurane }\end{array}$ & aerial parts & [238] \\
\hline $\begin{array}{l}\text { Thymus linearis Benth. } \\
\text { (Lamiaceae Lindl.) }\end{array}$ & thymol, carvacrol & aerial parts & [239] \\
\hline
\end{tabular}

Table 6. Not fully elucidated/not specified.

\begin{tabular}{|c|c|c|c|}
\hline Plant & Primary/Secondary Metabolite & Plant Part Used & Citation \\
\hline $\begin{array}{l}\text { Calpurnia aurea (Ait.) Benth. } \\
\text { (Fabaceae Lindl.) }\end{array}$ & & seeds & [240] \\
\hline $\begin{array}{l}\text { Vitex negundo L. } \\
\text { (Lamiaceae Lindl.) }\end{array}$ & & aerial parts & [241] \\
\hline $\begin{array}{l}\text { Ficcus saussureana DC } \\
\text { (Moraceae Dumort.) }\end{array}$ & & root bark & [242] \\
\hline $\begin{array}{l}\text { Prunus persica (L.) } \\
\quad \text { (Rosaceae L.) }\end{array}$ & & branches & [243] \\
\hline $\begin{array}{l}\text { Satureja obovata Lag. } \\
\text { (Lamiaceae Lindl.) }\end{array}$ & eriodictyol & & {$[244,245]$} \\
\hline $\begin{array}{c}\text { Vernonia amygdalina Del. } \\
\text { (Asteraceae Martinov) }\end{array}$ & alkaloids, flavonoids, saponins & leaves & [246] \\
\hline
\end{tabular}

\section{Conclusions}

The clinical relevance of endothelial dysfunction in patients with (not only) cardiovascular disorders remains subject to investigation. Although a number of vascular and non-vascular markers of endothelial dysfunction have been proposed, inexpensive, clinically accessible, optimal, and reproducible indicators still have not been found [247]. Nevertheless, it should always be considered that numerous plants and their metabolites may impact on the endothelium and affect its physiological functions. This may become even more important if the endothelium is disordered, as can be observed in numerous diseases. Therefore, patients should be actively informed about possible interactions between the prescribed medication and various dietary supplements or folk medicines containing substances with the potential to affect endothelial functions.

Further basic science and clinical studies are needed to better inform us about the therapeutic potential of and drug interferences from plant metabolites.

Author Contributions: A.B. was responsible for the literature search and writing the article. M.N. participated in the review and editing of the text. All authors have read and agreed to the published version of the manuscript.

Funding: This research was funded by Masaryk University as part of project numbers MUNI/A/1307/ 2019 and MUNI/A/1246/2020, with the support of the Specific University Research Grant, as pro- 
vided by the Ministry of Education, Youth, and Sports of the Czech Republic in the years 2020 and 2021. This research was supported by project number LQ1605 from the National Program of Sustainability II (MEYS CR).

Institutional Review Board Statement: Not applicable.

Informed Consent Statement: Not applicable.

Data Availability Statement: No new data were created or analyzed in this study. Data sharing is not applicable to this article.

Acknowledgments: The authors wish to thank Petr Babula for creating a supportive atmosphere and for fruitful discussions over the manuscript.

Conflicts of Interest: The authors declare no conflict of interest.

\begin{tabular}{|c|c|}
\hline \multicolumn{2}{|c|}{ Abbreviations } \\
\hline $\mathrm{AC}$ & adenylyl cyclase \\
\hline ACE & angiotensin-converting enzyme \\
\hline ARA & arachidonic acid \\
\hline AT I & angiotensin I \\
\hline AT II & angiotensin II \\
\hline $\mathrm{AT}_{1} \mathrm{R}$ & angiotensin II receptor type-1 \\
\hline ATP & adenosine triphosphate \\
\hline BK & bradykinin \\
\hline $\mathrm{C}$ & calmodulin \\
\hline cAMP & cyclic adenosine monophosphate \\
\hline cGMP & cyclic guanosine monophosphate \\
\hline CNP & natriuretic peptide $\mathrm{C}$ \\
\hline $\mathrm{CO}$ & carbon monoxide \\
\hline COX & cyclooxygenase \\
\hline COX-1 & cyclooxygenase 1 \\
\hline COX-2 & cyclooxygenase 2 \\
\hline CSF & colony-stimulating factor \\
\hline EC & endothelial cell \\
\hline ECE-1 & endothelin-converting enzyme 1 \\
\hline ECE-2 & endothelin-converting enzyme 2 \\
\hline ECE-3 & endothelin-converting enzyme 3 \\
\hline ECM & extracellular matrix \\
\hline $\mathrm{EDH}$ & endothelium-derived hyperpolarization \\
\hline $\mathrm{E}-\mathrm{D} \mathrm{H} \mathrm{H}_{2} \mathrm{O}_{2}$ & endothelium-derived $\mathrm{H}_{2} \mathrm{O}_{2}$ \\
\hline eNOS & endothelial nitric oxide synthase \\
\hline ER & endoplasmic reticulum \\
\hline ET & endothelin \\
\hline ET-1 & endothelin-1 \\
\hline ET-2 & endothelin-2 \\
\hline ET-3 & endothelin-3 \\
\hline $\mathrm{ET}_{\mathrm{A}}$ & receptor A for endothelin \\
\hline $\mathrm{ET}_{\mathrm{B} 1}$ & receptor B1 for endothelin \\
\hline $\mathrm{ET}_{\mathrm{B} 2}$ & receptor B2 for endothelin \\
\hline $\mathrm{ET}_{\mathrm{C}}$ & receptor $\mathrm{C}$ for endothelin \\
\hline GTP & guanosine triphosphate \\
\hline $\mathrm{H}_{2} \mathrm{~S}$ & hydrogen sulphide \\
\hline iACEs & angiotensin-converting enzyme inhibitors \\
\hline i-eNOS & endothelial nitric oxide synthase inhibition \\
\hline i-PGIS & prostacyclin synthase inhibition \\
\hline
\end{tabular}




\begin{tabular}{|c|c|}
\hline IGF & insulin-like growth factor \\
\hline iNOS & inducible nitric oxide synthase \\
\hline $\mathrm{K}_{\mathrm{Ca}}$ & $\mathrm{Ca}^{2+}$ activated $\mathrm{K}^{+}$channels \\
\hline L-arg & L-arginine \\
\hline LDL-receptor & low-density lipoprotein receptor \\
\hline $\mathrm{MH}$ & membrane hyperpolarization \\
\hline MHC II & major histocompatibility complex type 2 \\
\hline $\mathrm{N}$ & nucleus \\
\hline nNOS & neural nitric oxide synthase \\
\hline NO & nitric oxide \\
\hline NO-cGMP & nitric oxide-cyclic guanosine monophosphate \\
\hline NOS & nitric oxide synthase \\
\hline PAF & platelet-activating factor \\
\hline PAI & plasminogen activator inhibitor \\
\hline PDE & phosphodiesterase \\
\hline $\mathrm{PGH}_{2}$ & prostaglandin $\mathrm{H}_{2}$ \\
\hline $\mathrm{PGI}_{2}$ & prostacyclin \\
\hline PGI2-cAMP & prostacyclin-cyclic adenosine monophosphate \\
\hline PGIS & prostacyclin synthase \\
\hline $\mathrm{R}$ & receptor \\
\hline RAAS & renin-angiotensin-aldosterone system \\
\hline ROCC & receptor-operated $\mathrm{Ca}^{2+}$ channels \\
\hline ROS & reactive oxygen species \\
\hline sGC & soluble receptor with guanylate cyclase activity \\
\hline SMC & smooth muscle cell \\
\hline $\mathrm{SOCa} \mathrm{Ca}^{2+}$ & store-operated $\mathrm{Ca}^{2+}$ channels \\
\hline SR & sarcoplasmic reticulum \\
\hline SS & shear stress \\
\hline TGF & transforming growth factor \\
\hline TPR & thromboxane $\mathrm{A}_{2}$-prostanoid receptor \\
\hline $\mathrm{TXA}_{2}$ & thromboxane $\mathrm{A}_{2}$ \\
\hline TXAS & thromboxane synthase \\
\hline VDCC & voltage-dependent $\mathrm{Ca}^{2+}$ channels \\
\hline VEGF & vascular endothelial growth factor \\
\hline vIF & various inactive fragments \\
\hline vRF & various reactive fragments \\
\hline VSMC & vascular smooth muscle cell \\
\hline vWf & von Willebrand's factor \\
\hline
\end{tabular}

\section{References}

1. Sumpio, B.E.; Riley, J.T.; Dardik, A. Cells in focus: Endothelial cell. Int. J. Biochem. Cell Biol. 2002, 34, 1508-1512. [CrossRef]

2. Roberts, D.M.; Kearney, J.B.; Johnson, J.H.; Rosenberg, M.P.; Kumar, R.; Bautch, V.L. The vascular endothelial growth factor (VEGF) receptor Flt-1 (VEGFR-1) modulates Flk-1 (VEGFR-2) signaling during blood vessel formation. Am. J. Pathol. 2004, 164, 1531-1535. [CrossRef]

3. Patan, S. Vasculogenesis and angiogenesis. Cancer Treat. Res. 2004, 117, 3-32. [CrossRef] [PubMed]

4. Kajdaniuk, D.; Marek, B.; Borgiel-Marek, H.; Kos-Kudła, B. Vascular endothelial growth factor (VEGF)—Part 1: In physiology and pathophysiology. Endokrynol. Pol. 2011, 62, 444-455.

5. Fels, J.; Jeggle, P.; Liashkovich, I.; Peters, W.; Oberleithner, H. Nanomechanics of vascular endothelium. Cell Tissue Res. 2014, 355, 727-737. [CrossRef]

6. Galley, H.F.; Webster, N.R. Physiology of the endothelium. Br. J. Anaesth. 2004, 93, 105-113. [CrossRef]

7. Shimokawa, H.; Godo, S. Nitric oxide and endothelium-dependent hyperpolarization mediated by hydrogen peroxide in health and disease. Basic Clin. Pharmacol. Toxicol. 2020, 127, 92-101. [CrossRef] [PubMed]

8. Laroia, S.T.; Ganti, A.K.; Laroia, A.T.; Tendulkar, K.K. Endothelium and the lipid metabolism: The current understanding. Int J. Cardiol. 2003, 88, 1-9. [CrossRef]

9. Ballermann, B.J.; Dardik, A.; Eng, E.; Liu, A. Shear stress and the endothelium. Kidney Int. Suppl. 1998, 67, S100-S108. [CrossRef] 
10. Landmesser, U.; Drexler, H. Effect of angiotensin II type 1 receptor antagonism on endothelial function: Role of bradykinin and nitric oxide. J. Hypertens. Suppl. 2006, 24, S39-S43. [CrossRef]

11. Watanabe, T.; Barker, T.A.; Berk, B.C. Angiotensin II and the endothelium: Diverse signals and effects. Hypertension 2005, 45, 163-169. [CrossRef]

12. Parsaee, H.; McEwan, J.R.; MacDermot, J. Bradykinin-induced release of PGI2 from aortic endothelial cell lines: Responses mediated selectively by Ca2+ ions or a staurosporine-sensitive kinase. Br. J. Pharmacol. 1993, 110, 411-415. [CrossRef] [PubMed]

13. Kumar, K.V.; Das, U.N. Are free radicals involved in the pathobiology of human essential hypertension? Free Radic. Res. Commun. 1993, 19, 59-66. [CrossRef]

14. Barbosa-Filho, J.M.; Martins, V.K.M.; Rabelo, L.A.; Moura, M.D.; Silva, M.S.; Cunha, E.V.L.; Souza, M.F.V.; Almeida, R.N.; Medeiros, I.A. Natural products inhibitors of the angiotensin converting enzyme (ACE)s: A review between 1980-2000. Rev. Bras. Farmacogn. 2006, 16, 421-446. [CrossRef]

15. Fyhrquist, F.; Metsärinne, K.; Tikkanen, I. Role of angiotensin II in blood pressure regulation and in the pathophysiology of cardiovascular disorders. J. Hum. Hypertens. 1995, 9 (Suppl. 5), S19-S24.

16. Ferrario, C.M. Role of angiotensin II in cardiovascular disease therapeutic implications of more than a century of research. $J$. Renin. Angiotensin. Aldosterone Syst. 2006, 7, 3-14. [CrossRef] [PubMed]

17. Stoll, M.; Steckelings, U.M.; Paul, M.; Bottari, S.P.; Metzger, R.; Unger, T. The angiotensin AT2-receptor mediates inhibition of cell proliferation in coronary endothelial cells. J. Clin. Invest. 1995, 95, 651-657. [CrossRef]

18. Wong, M.K.S. Bradykinin. In Handbook of Hormones: Comparative Endocrinology for Basic and Clinical Research; Takei, Y., Ando, H., Tsutsui, K., Eds.; Academic Press Ltd-Elsevier Science Ltd.: London, UK, 2016; p. 274. [CrossRef]

19. Tomiyama, H.; Kushiro, T.; Abeta, H.; Ishii, T.; Takahashi, A.; Furukawa, L.; Asagami, T.; Hino, T.; Saito, F.; Otsuka, Y. Kinins contribute to the improvement of insulin sensitivity during treatment with angiotensin converting enzyme inhibitor. Hypertension 1994, 23, 450-455. [CrossRef]

20. Greaney, J.L.; Kutz, J.L.; Shank, S.W.; Jandu, S.; Santhanam, L.; Alexander, L.M. Impaired Hydrogen Sulfide-Mediated Vasodilation Contributes to Microvascular Endothelial Dysfunction in Hypertensive Adults. Hypertension 2017, 69, 902-909. [CrossRef] [PubMed]

21. Vallance, P.; Hingorani, A. Endothelial nitric oxide in humans in health and disease. Int. J. Exp. Pathol. 1999, 80, 291-303. [CrossRef]

22. Ghalayini, I.F. Nitric oxide-cyclic GMP pathway with some emphasis on cavernosal contractility. Int. J. Impot. Res. 2004, 16, 459-469. [CrossRef] [PubMed]

23. Ahmad, A.; Khan, R.M.; Alkharfy, K.M. Effects of selected bioactive natural products on the vascular endothelium. J. Cardiovasc. Pharmacol. 2013, 62, 111-121. [CrossRef]

24. Ozkor, M.A.; Quyyumi, A.A. Endothelium-derived hyperpolarizing factor and vascular function. Cardiol. Res. Pract. 2011, 2011, 156146. [CrossRef]

25. Yang, P.M.; Huang, Y.T.; Zhang, Y.Q.; Hsieh, C.W.; Wung, B.S. Carbon monoxide releasing molecule induces endothelial nitric oxide synthase activation through a calcium and phosphatidylinositol 3-kinase/Akt mechanism. Vascul. Pharmacol. 2016, 87, 209-218. [CrossRef] [PubMed]

26. Jankovic, G.; Marinko, M.; Milojevic, P.; Stojanovic, I.; Nenezic, D.; Kanjuh, V.; Yang, Q.; He, G.W.; Novakovic, A. Mechanisms of endothelium-dependent vasorelaxation induced by procyanidin B2 in venous bypass graft. J. Pharmacol. Sci. 2020, 142, 101-108. [CrossRef]

27. Li, H.; Xia, N.; Brausch, I.; Yao, Y.; Förstermann, U. Flavonoids from artichoke (Cynara scolymus L.) up-regulate endothelial-type nitric-oxide synthase gene expression in human endothelial cells. J. Pharmacol. Exp. Ther. 2004, 310, 926-932. [CrossRef] [PubMed]

28. Yu, J.; Eto, M.; Akishita, M.; Kaneko, A.; Ouchi, Y.; Okabe, T. Signaling pathway of nitric oxide production induced by ginsenoside $\mathrm{Rb} 1$ in human aortic endothelial cells: A possible involvement of androgen receptor. Biochem Biophys Res. Commun. 2007, 353, 764-769. [CrossRef]

29. Fisher, N.D.; Hughes, M.; Gerhard-Herman, M.; Hollenberg, N.K. Flavanol-rich cocoa induces nitric-oxide-dependent vasodilation in healthy humans. J. Hypertens. 2003, 21, 2281-2286. [CrossRef] [PubMed]

30. Moncada, S.; Vane, J.R. Interrelationships between prostacyclin and thromboxane A2. Ciba Found. Symp. 1980, 78, 165-183. [CrossRef] [PubMed]

31. Majed, B.H.; Khalil, R.A. Molecular mechanisms regulating the vascular prostacyclin pathways and their adaptation during pregnancy and in the newborn. Pharmacol. Rev. 2012, 64, 540-582. [CrossRef] [PubMed]

32. Sandoo, A.; van Zanten, J.J.; Metsios, G.S.; Carroll, D.; Kitas, G.D. The endothelium and its role in regulating vascular tone. Open Cardiovasc. Med. J. 2010, 4, 302-312. [CrossRef] [PubMed]

33. Luna-Vázquez, F.J.; Ibarra-Alvarado, C.; Rojas-Molina, A.; Rojas-Molina, I.; Zavala-Sánchez, M.A. Vasodilator compounds derived from plants and their mechanisms of action. Molecules 2013, 18, 5814-5857. [CrossRef] [PubMed]

34. Raimundo, J.M.; Trindade, A.P.; Velozo, L.S.; Kaplan, M.A.; Sudo, R.T.; Zapata-Sudo, G. The lignan eudesmin extracted from Piper truncatum induced vascular relaxation via activation of endothelial histamine H1 receptors. Eur. J. Pharmacol. 2009, 606, 150-154. [CrossRef] [PubMed]

35. Raimundo, J.M.; de Almeida, R.R.; Velozo, L.S.; Kaplan, M.A.; Gattass, C.R.; Zapata-Sudo, G. In-vitro vasodilatory activity of the hexanic extract of leaves and stems from Piper truncatum Vell. in rats. J. Pharm. Pharmacol. 2004, 56, 1457-1462. [CrossRef] 
36. Chau, Y.; Li, F.S.; Levsh, O.; Weng, J.K. Exploration of icariin analog structure space reveals key features driving potent inhibition of human phosphodiesterase-5. PLoS ONE 2019, 14, e0222803. [CrossRef] [PubMed]

37. Lan, T.H.; Chen, X.L.; Wu, Y.S.; Qiu, H.L.; Li, J.Z.; Ruan, X.M.; Xu, D.P.; Lin, D.Q. 3,7-Bis(2-hydroxyethyl)icaritin, a potent inhibitor of phosphodiesterase-5, prevents monocrotaline-induced pulmonary arterial hypertension via NO/cGMP activation in rats. Eur. J. Pharmacol. 2018, 829, 102-111. [CrossRef] [PubMed]

38. Garland, C.J.; Hiley, C.R.; Dora, K.A. EDHF: Spreading the influence of the endothelium. Br. J. Pharmacol. 2011, 164, 839-852. [CrossRef]

39. Knox, M.; Vinet, R.; Fuentes, L.; Morales, B.; Martínez, J.L. A Review of Endothelium-Dependent and -Independent Vasodilation Induced by Phytochemicals in Isolated Rat Aorta. Animals 2019, 9, 623. [CrossRef]

40. Lumsden, N.G.; Khambata, R.S.; Hobbs, A.J. C-type natriuretic peptide (CNP): Cardiovascular roles and potential as a therapeutic target. Curr. Pharm. Des. 2010, 16, 4080-4088. [CrossRef]

41. Mustafa, A.K.; Sikka, G.; Gazi, S.K.; Steppan, J.; Jung, S.M.; Bhunia, A.K.; Barodka, V.M.; Gazi, F.K.; Barrow, R.K.; Wang, R.; et al. Hydrogen sulfide as endothelium-derived hyperpolarizing factor sulfhydrates potassium channels. Circ. Res. 2011, 109, 1259-1268. [CrossRef]

42. Bhatia, M. Hydrogen sulfide as a vasodilator. IUBMB Life 2005, 57, 603-606. [CrossRef]

43. Mombouli, J.V.; Bissiriou, I.; Agboton, V.; Vanhoutte, P.M. Endothelium-derived hyperpolarizing factor: A key mediator of the vasodilator action of bradykinin. Immunopharmacology 1996, 33, 46-50. [CrossRef]

44. Van Hinsbergh, V.W. Endothelium-Role in regulation of coagulation and inflammation. Semin. Immunopathol. 2012, 34, 93-106. [CrossRef] [PubMed]

45. Goldberg, I.J.; Bornfeldt, K.E. Lipids and the endothelium: Bidirectional interactions. Curr. Atheroscler. Rep. 2013, 15, 365. [CrossRef]

46. García, X.; Cartas-Heredia, L.; Lorenzana-Jímenez, M.; Gijón, E. Vasoconstrictor effect of Cissus sicyoides on guinea-pig aortic rings. Gen. Pharmacol. 1997, 29, 457-462. [CrossRef]

47. Bull, H.A.; Pittilo, R.M.; Blow, D.J.; Blow, C.M.; Rowles, P.M.; Woolf, N.; Machin, S.J. The effects of nicotine on PGI2 production by rat aortic endothelium. Thromb. Haemost. 1985, 54, 472-474. [CrossRef] [PubMed]

48. Oakes, J.M.; Xu, J.; Morris, T.M.; Fried, N.D.; Pearson, C.S.; Lobell, T.D.; Gilpin, N.W.; Lazartigues, E.; Gardner, J.D.; Yue, X. Effects of Chronic Nicotine Inhalation on Systemic and Pulmonary Blood Pressure and Right Ventricular Remodeling in Mice. Hypertension 2020, 75, 1305-1314. [CrossRef] [PubMed]

49. Wölfle, U.; Hoffmann, J.; Haarhaus, B.; Rao Mittapalli, V.; Schempp, C.M. Anti-inflammatory and vasoconstrictive properties of Potentilla erecta-A traditional medicinal plant from the northern hemisphere. J. Ethnopharmacol. 2017, 204, 86-94. [CrossRef] [PubMed]

50. Hayat-Malik, M.N.; Bashir, S.; Khan, I.U.; Karim, S.; Mushtaq, M.N.; Khan, H.U.; Rashid, M.; Naz, H.; Samreen, S. Cardiotonic and vasoconstriction effects of aqueous methanolic extract of Paspalidium flavidum L. Pak. J. Pharm. Sci. 2015, 28, 437-441.

51. Gilani, A.U.H.; Shaheen, F. Vasoconstrictor and cardiotonic actions of Haloxylon-recurvum extract. Phytother. Res. 1994, 8, 115-117. [CrossRef]

52. Wahab, A.; Ahmed, E.; Nawaz, S.A.; Sharif, A.; Ul Haq, R.; Malik, A.; Choudhary, M.I.; Raza, M. A pharmacological and toxicological evaluation of Haloxylon recurvum. Nat. Prod. Res. 2008, 22, 1317-1326. [CrossRef]

53. Chen, H. Role of thromboxane A. Prostaglandins Other Lipid Med. 2018, 134, 32-37. [CrossRef]

54. Rucker, D.; Dhamoon, A.S. Physiology, Thromboxane A2. In StatPearls; StatPearls Publishing: Treasure Island, FL, USA, 2020.

55. Grann, M.; Comerma-Steffensen, S.; Arcanjo, D.D.; Simonsen, U. Mechanisms Involved in Thromboxane A. Basic Clin. Pharmacol. Toxicol. 2016, 119 (Suppl. 3), 86-95. [CrossRef]

56. Caughey, G.E.; Cleland, L.G.; Penglis, P.S.; Gamble, J.R.; James, M.J. Roles of cyclooxygenase (COX)-1 and COX-2 in prostanoid production by human endothelial cells: Selective up-regulation of prostacyclin synthesis by COX-2. J. Immunol. 2001, 167, 2831-2838. [CrossRef] [PubMed]

57. Davenport, A.P.; Hyndman, K.A.; Dhaun, N.; Southan, C.; Kohan, D.E.; Pollock, J.S.; Pollock, D.M.; Webb, D.J.; Maguire, J.J. Endothelin. Pharmacol. Rev. 2016, 68, 357-418. [CrossRef]

58. Drawnel, F.M.; Archer, C.R.; Roderick, H.L. The role of the paracrine/autocrine mediator endothelin-1 in regulation of cardiac contractility and growth. Br. J. Pharmacol. 2013, 168, 296-317. [CrossRef] [PubMed]

59. Barton, M.; Yanagisawa, M. Endothelin: 30 Years From Discovery to Therapy. Hypertension 2019, 74, 1232-1265. [CrossRef] [PubMed]

60. Stow, L.R.; Jacobs, M.E.; Wingo, C.S.; Cain, B.D. Endothelin-1 gene regulation. FASEB J. 2011, 25, 16-28. [CrossRef] [PubMed]

61. Unic, A.; Derek, L.; Hodak, N.; Marijancevic, D.; Ceprnja, M.; Serdar, T.; Krhac, M.; Romic, Z. Endothelins-Clinical perspectives. Biochem. Med. 2011, 21, 231-242. [CrossRef]

62. Camussi, G.; Tetta, C.; Baglioni, C. The role of platelet-activating factor in inflammation. Clin. Immunol. Immunopathol. 1990, 57, 331-338. [CrossRef]

63. Majewski, M. Allium sativum: Facts and myths regarding human health. Rocz. Panstw. Zakl. Hig. 2014, 65, 1-8.

64. Ashraf, R.; Khan, R.A.; Ashraf, I.; Qureshi, A.A. Effects of Allium sativum (garlic) on systolic and diastolic blood pressure in patients with essential hypertension. Pak. J. Pharm. Sci. 2013, 26, 859-863. 
65. El-Saber Batiha, G.; Magdy Beshbishy, A.; G Wasef, L.; Elewa, Y.H.A.; A Al-Sagan, A.; Abd El-Hack, M.E.; Taha, A.E.; M AbdElhakim, Y.; Prasad Devkota, H. Chemical Constituents and Pharmacological Activities of Garlic (Allium sativum L.). Nutrients 2020, 12, 872. [CrossRef] [PubMed]

66. Pedraza-Chaverrí, J.; Tapia, E.; Medina-Campos, O.N.; de los Angeles Granados, M.; Franco, M. Garlic prevents hypertension induced by chronic inhibition of nitric oxide synthesis. Life Sci. 1998, 62, PL71-PL77. [CrossRef]

67. Victorio, C.P.; Kuster, R.M.; de Moura, R.S.; Lage, C.L.S. Vasodilator activity of extracts of field Alpinia purpurata (Vieill) K. Schum and A. zerumbet (Pers.) Burtt et Smith cultured in vitro. Braz. J. Pharm. Sci. 2009, 45, 507-514. [CrossRef]

68. De Moura, R.S.; Emiliano, A.F.; de Carvalho, L.C.; Souza, M.A.; Guedes, D.C.; Tano, T.; Resende, A.C. Antihypertensive and endothelium-dependent vasodilator effects of Alpinia zerumbet, a medicinal plant. J. Cardiovasc. Pharmacol. 2005, 46, 288-294. [CrossRef]

69. Afkir, S.; Nguelefack, T.B.; Aziz, M.; Zoheir, J.; Cuisinaud, G.; Bnouham, M.; Mekhfi, H.; Legssyer, A.; Lahlou, S.; Ziyyat, A. Arbutus unedo prevents cardiovascular and morphological alterations in L-NAME-induced hypertensive rats Part I: Cardiovascular and renal hemodynamic effects of Arbutus unedo in L-NAME-induced hypertensive rats. J. Ethnopharmacol. 2008, 116, 288-295. [CrossRef]

70. Xie, Y.W.; Ming, D.S.; Xu, H.X.; Dong, H.; But, P.P. Vasorelaxing effects of Caesalpinia sappan involvement of endogenous nitric oxide. Life Sci. 2000, 67, 1913-1918. [CrossRef]

71. Hu, C.M.; Kang, J.J.; Lee, C.C.; Li, C.H.; Liao, J.W.; Cheng, Y.W. Induction of vasorelaxation through activation of nitric oxide synthase in endothelial cells by brazilin. Eur. J. Pharmacol. 2003, 468, 37-45. [CrossRef]

72. Cherkaoui-Tangi, K.; Lachkar, M.; Wibo, M.; Morel, N.; Gilani, A.H.; Lyoussi, B. Pharmacological studies on hypotensive, diuretic and vasodilator activities of chrysin glucoside from Calycotome villosa in rats. Phytother. Res. 2008, 22, 356-361. [CrossRef] [PubMed]

73. Villar, I.C.; Vera, R.; Galisteo, M.; O`Valle, F.; Romero, M.; Zarzuelo, A.; Duarte, J. Endothelial nitric oxide production stimulated by the bioflavonoid chrysin in rat isolated aorta. Planta Med. 2005, 71, 829-834. [CrossRef]

74. Duarte, J.; Jiménez, R.; Villar, I.C.; Pérez-Vizcaíno, F.; Jiménez, J.; Tamargo, J. Vasorelaxant effects of the bioflavonoid chrysin in isolated rat aorta. Planta Med. 2001, 67, 567-569. [CrossRef] [PubMed]

75. Assreuy, A.M.; Fontenele, S.R.; Pires, A.e.F.; Fernandes, D.C.; Rodrigues, N.V.; Bezerra, E.H.; Moura, T.R.; do Nascimento, K.S.; Cavada, B.S. Vasodilator effects of Diocleinae lectins from the Canavalia genus. Naunyn Schmiedebergs Arch. Pharmacol. 2009, 380, 509-521. [CrossRef] [PubMed]

76. Barroso-Neto, I.L.; Simões, R.C.; Rocha, B.A.; Bezerra, M.J.; Pereira-Junior, F.N.; Silva Osterne, V.J.; Nascimento, K.S.; Nagano, C.S.; Delatorre, P.; Pereira, M.G.; et al. Vasorelaxant activity of Canavalia grandiflora seed lectin: A structural analysis. Arch. Biochem. Biophys. 2014, 543, 31-39. [CrossRef] [PubMed]

77. Zhang, Y.; Cao, Y.; Duan, H.; Wang, H.; He, L. Imperatorin prevents cardiac hypertrophy and the transition to heart failure via NO-dependent mechanisms in mice. Fitoterapia 2012, 83, 60-66. [CrossRef]

78. Bertin, R.; Chen, Z.; Martínez-Vázquez, M.; García-Argaéz, A.; Froldi, G. Vasodilation and radical-scavenging activity of imperatorin and selected coumarinic and flavonoid compounds from genus Casimiroa. Phytomedicine 2014, 21, 586-594. [CrossRef]

79. Vinet, R.; Cortes, M.; Alvarez, R.; Guzman, L.; Flores, E. Centaurium cachanlahuen (Mol.) Robinson, a Chilean native plant with a vasodilatory effect. Bol. Latinoam. Caribe Plantas Med. Aromat. 2012, 11, 61-65.

80. Belmokhtar, M.; Bouanani, N.E.; Ziyyat, A.; Mekhfi, H.; Bnouham, M.; Aziz, M.; Matéo, P.; Fischmeister, R.; Legssyer, A. Antihypertensive and endothelium-dependent vasodilator effects of aqueous extract of Cistus ladaniferus. Biochem. Biophys. Res. Commun. 2009, 389, 145-149. [CrossRef] [PubMed]

81. Kosala, K.; Ismail, S.; Fikriah, I.; Magdaleni, A.R. In vitro Exploration of Vasodilation Activity of the Methanol Extract of the Coptosapelta flavescens Korth stem. J. Islam. Med. Res. 2017, 1, 10-14.

82. Generalić Mekinić, I.; Blažević, I.; Mudnić, I.; Burčul, F.; Grga, M.; Skroza, D.; Jerčić, I.; Ljubenkov, I.; Boban, M.; Miloš, M.; et al. Sea fennel (Crithmum maritimum L.): Phytochemical profile, antioxidative, cholinesterase inhibitory and vasodilatory activity. $J$. Food Sci Technol 2016, 53, 3104-3112. [CrossRef]

83. Guerrero, M.F.; Puebla, P.; Carrón, R.; Martín, M.L.; Arteaga, L.; Román, L.S. Assessment of the antihypertensive and vasodilator effects of ethanolic extracts of some Colombian medicinal plants. J. Ethnopharmacol. 2002, 80, 37-42. [CrossRef]

84. Paez, M.T.; Rodriguez, D.C.; Lopez, D.F.; Castaneda, J.A.; Buitrago, D.M.; Cuca, L.E.; Guerrero, M.F. Croton schiedeanus Schltd prevents experimental hypertension in rats induced by nitric oxide deficit. Braz. J. Pharm. Sci. 2013, 49, 865-871. [CrossRef]

85. Guerrero, M.F.; Puebla, P.; Carrón, R.; Martín, M.L.; San Román, L. Quercetin 3,7-dimethyl ether: A vasorelaxant flavonoid isolated from Croton schiedeanus Schlecht. J. Pharm. Pharmacol. 2002, 54, 1373-1378. [CrossRef] [PubMed]

86. Mendes, L.J.; Capettini, L.S.; Lôbo, L.T.; da Silva, G.A.; Arruda, M.S.; Lemos, V.S.; Côrtes, S.F. Endothelial nitric oxide-dependent vasorelaxant effect of isotirumalin, a dihydroflavonol from Derris urucu, on the rat aorta. Biol. Pharm. Bull. 2011, 34, 1499-1500. [CrossRef] [PubMed]

87. Lobo, L.T.; da Silva, G.A.; Ferreira, M.; da Silva, M.N.; Santos, A.S.; Arruda, A.C.; Guilhon, G.; Santos, L.S.; Borges, R.D.; Arruda, M.S.P. Dihydroflavonols from the leaves of Derris urucu (Leguminosae): Structural Elucidation and DPPH Radical-Scavenging Activity. J. Braz. Chem. Soc. 2009, 20, 1082-1088. [CrossRef] 
88. Rocha, A.P.; Carvalho, L.C.; Sousa, M.A.; Madeira, S.V.; Sousa, P.J.; Tano, T.; Schini-Kerth, V.B.; Resende, A.C.; Soares de Moura, R. Endothelium-dependent vasodilator effect of Euterpe oleracea Mart. (Açaí) extracts in mesenteric vascular bed of the rat. Vascul. Pharmacol. 2007, 46, 97-104. [CrossRef] [PubMed]

89. Xie, Y.W.; Xu, H.X.; Dong, H.; Fiscus, R.R.; But, P.P. Role of nitric oxide in the vasorelaxant and hypotensive effects of extracts and purified tannins from Geum japonicum. J. Ethnopharmacol. 2007, 109, 128-133. [CrossRef]

90. Chen, X.; Salwinski, S.; Lee, T.J.F. Extracts of Ginkgo biloba and ginsenosides exert cerebral vasorelaxation via a nitric oxide pathway. Clin. Exp. Pharm. Physiol. 1997, 24, 958-959. [CrossRef]

91. Nishida, S.; Satoh, H. Mechanisms for the vasodilations induced by Ginkgo biloba extract and its main constituent, bilobalide, in rat aorta. Life Sci. 2003, 72, 2659-2667. [CrossRef]

92. Hakkou, Z.; Maciuk, A.; Leblais, V.; Bouanani, N.E.; Mekhfi, H.; Bnouham, M.; Aziz, M.; Ziyyat, A.; Rauf, A.; Hadda, T.B.; et al. Antihypertensive and vasodilator effects of methanolic extract of Inula viscosa: Biological evaluation and POM analysis of cynarin, chlorogenic acid as potential hypertensive. Biomed. Pharmacother. 2017, 93, 62-69. [CrossRef]

93. Del Valle-Mondragón, L.; Tenorio-López, F.A.; Zarco-Olvera, G.; Pastelín-Hernández, G. Vulgarenol, a sesquiterpene isolated from Magnolia grandiflora, induces nitric oxide synthases II and III overexpression in guinea pig hearts. Z. Naturforsch. C J. Biosci. 2007, 62, 725-730. [CrossRef]

94. Zamblé, A.; Martin-Nizard, F.; Sahpaz, S.; Reynaert, M.L.; Staels, B.; Bordet, R.; Duriez, P.; Gressier, B.; Bailleul, F. Effects of Microdesmis keayana alkaloids on vascular parameters of erectile dysfunction. Phytother. Res. 2009, 23, 892-895. [CrossRef]

95. Interaminense, L.F.; Leal-Cardoso, J.H.; Magalhães, P.J.; Duarte, G.P.; Lahlou, S. Enhanced hypotensive effects of the essential oil of Ocimum gratissimum leaves and its main constituent, eugenol, in DOCA-salt hypertensive conscious rats. Planta Med. 2005, 71, 376-378. [CrossRef]

96. Pires, A.F.; Madeira, S.V.; Soares, P.M.; Montenegro, C.M.; Souza, E.P.; Resende, A.C.; Soares de Moura, R.; Assreuy, A.M.; Criddle, D.N. The role of endothelium in the vasorelaxant effects of the essential oil of Ocimum gratissimum in aorta and mesenteric vascular bed of rats. Can. J. Physiol. Pharmacol. 2012, 90, 1380-1385. [CrossRef]

97. Yoo, M.Y.; Lee, B.H.; Choi, Y.H.; Lee, J.W.; Seo, J.H.; Oh, K.S.; Koo, H.N.; Seo, H.W.; Yon, G.H.; Kwon, D.Y.; et al. Vasorelaxant effect of the rootbark extract of Paeonia moutan on isolated rat thoracic aorta. Planta Med. 2006, 72, 1338-1341. [CrossRef]

98. Kim, Y.M.; Namkoong, S.; Yun, Y.G.; Hong, H.D.; Lee, Y.C.; Ha, K.S.; Lee, H.; Kwon, H.J.; Kwon, Y.G. Water extract of Korean red ginseng stimulates angiogenesis by activating the PI3K/Akt-dependent ERK1/2 and eNOS pathways in human umbilical vein endothelial cells. Biol. Pharm. Bull. 2007, 30, 1674-1679. [CrossRef]

99. Leung, K.W.; Cheng, Y.K.; Mak, N.K.; Chan, K.K.; Fan, T.P.; Wong, R.N. Signaling pathway of ginsenoside-Rg1 leading to nitric oxide production in endothelial cells. FEBS Lett. 2006, 580, 3211-3216. [CrossRef] [PubMed]

100. Xia, N.; Bollinger, L.; Steinkamp-Fenske, K.; Förstermann, U.; Li, H. Prunella vulgaris L. Upregulates eNOS expression in human endothelial cells. Am. J. Chin. Med. 2010, 38, 599-611. [CrossRef] [PubMed]

101. Gu, X.; Li, Y.; Mu, J.; Zhang, Y. Chemical constituents of Prunella vulgaris. J. Environ. Sci. 2013, 25 (Suppl. 1), S161-S163. [CrossRef]

102. Sham, T.T.; Yuen, A.C.; Ng, Y.F.; Chan, C.O.; Mok, D.K.; Chan, S.W. A review of the phytochemistry and pharmacological activities of raphani semen. Evid. Based Complement. Alternat. Med. 2013, 2013, 636194. [CrossRef] [PubMed]

103. Chung, D.H.; Kim, S.H.; Myung, N.; Cho, K.J.; Chang, M.J. The antihypertensive effect of ethyl acetate extract of radish leaves in spontaneously hypertensive rats. Nutr. Res. Pract. 2012, 6, 308-314. [CrossRef] [PubMed]

104. Moon, M.K.; Kang, D.G.; Lee, J.K.; Kim, J.S.; Lee, H.S. Vasodilatory and anti-inflammatory effects of the aqueous extract of rhubarb via a NO-cGMP pathway. Life Sci. 2006, 78, 1550-1557. [CrossRef] [PubMed]

105. Oh, K.S.; Ryu, S.Y.; Kim, Y.S.; Lee, B.H. Large conductance $\mathrm{Ca}^{2+}$-activated $\mathrm{K}^{+}(\mathrm{BKCa})$ channels are involved in the vascular relaxations elicited by piceatannol isolated from Rheum undulatum rhizome. Planta Med. 2007, 73, 1441-1446. [CrossRef]

106. Yoo, M.Y.; Oh, K.S.; Lee, J.W.; Seo, H.W.; Yon, G.H.; Kwon, D.Y.; Kim, Y.S.; Ryu, S.Y.; Lee, B.H. Vasorelaxant effect of stilbenes from rhizome extract of rhubarb (Rheum undulatum) on the contractility of rat aorta. Phytother. Res. 2007, 21, 186-189. [CrossRef] [PubMed]

107. Oh, K.S.; Choi, Y.H.; Ryu, S.Y.; Oh, B.K.; Seo, H.W.; Yon, G.H.; Kim, Y.S.; Lee, B.H. Cardiovascular effects of lignans isolated from Saururus chinensis. Planta Med. 2008, 74, 233-238. [CrossRef]

108. Kang, D.G.; Yin, M.H.; Oh, H.; Lee, D.H.; Lee, H.S. Vasorelaxation by amentoflavone isolated from Selaginella tamariscina. Planta Med. 2004, 70, 718-722. [CrossRef]

109. Yu, S.; Yan, H.; Zhang, L.; Shan, M.; Chen, P.; Ding, A.; Li, S.F. A Review on the Phytochemistry, Pharmacology, and Pharmacokinetics of Amentoflavone, a Naturally-Occurring Biflavonoid. Molecules 2017, 22, 299. [CrossRef]

110. Vinet, R.; Alvarez, R.; Knox, M.; Guzman, L.; Martinez, J.L.; Flores, E. Vasodilatory properties of Solanum crispum Ruiz \& Pav. a South American native plant. Bol. Latinoam. Caribe Plantas Med. Aromat 2016, 15, 94-98.

111. Zaima, K.; Koga, I.; Iwasawa, N.; Hosoya, T.; Hirasawa, Y.; Kaneda, T.; Ismail, I.S.; Lajis, N.H.; Morita, H. Vasorelaxant activity of indole alkaloids from Tabernaemontana dichotoma. J. Nat. Med. 2013, 67, 9-16. [CrossRef]

112. Rodrigues, A.M.; Guimarães, D.O.; Konno, T.U.; Tinoco, L.W.; Barth, T.; Aguiar, F.A.; Lopes, N.P.; Leal, I.C.; Raimundo, J.M.; Muzitano, M.F. Phytochemical Study of Tapirira guianensis Leaves Guided by Vasodilatory and Antioxidant Activities. Molecules 2017, 22, 304. [CrossRef] [PubMed] 
113. Schroeter, H.; Heiss, C.; Balzer, J.; Kleinbongard, P.; Keen, C.L.; Hollenberg, N.K.; Sies, H.; Kwik-Uribe, C.; Schmitz, H.H.; Kelm, M. (-)-Epicatechin mediates beneficial effects of flavanol-rich cocoa on vascular function in humans. Proc. Natl. Acad. Sci. USA 2006, 103, 1024-1029. [CrossRef]

114. Grassi, D.; Necozione, S.; Lippi, C.; Croce, G.; Valeri, L.; Pasqualetti, P.; Desideri, G.; Blumberg, J.B.; Ferri, C. Cocoa reduces blood pressure and insulin resistance and improves endothelium-dependent vasodilation in hypertensives. Hypertension 2005, 46, 398-405. [CrossRef] [PubMed]

115. Faridi, Z.; Njike, V.Y.; Dutta, S.; Ali, A.; Katz, D.L. Acute dark chocolate and cocoa ingestion and endothelial function: A randomized controlled crossover trial. Am. J. Clin. Nutr. 2008, 88, 58-63. [CrossRef]

116. Karim, M.; McCormick, K.; Kappagoda, C.T. Effects of cocoa extracts on endothelium-dependent relaxation. J. Nutr. 2000, 130, 2105S-2108S. [CrossRef]

117. Seya, K.; Furukawa, K.; Taniguchi, S.; Kodzuka, G.; Oshima, Y.; Niwa, M.; Motomura, S. Endothelium-dependent vasodilatory effect of vitisin C, a novel plant oligostilbene from Vitis plants (Vitaceae), in rabbit aorta. Clin. Sci. 2003, 105, 73-79. [CrossRef] [PubMed]

118. Soares De Moura, R.; Costa Viana, F.S.; Souza, M.A.; Kovary, K.; Guedes, D.C.; Oliveira, E.P.; Rubenich, L.M.; Carvalho, L.C.; Oliveira, R.M.; Tano, T.; et al. Antihypertensive, vasodilator and antioxidant effects of a vinifera grape skin extract. J. Pharm. Pharmacol. 2002, 54, 1515-1520. [CrossRef] [PubMed]

119. Leifert, W.R.; Abeywardena, M.Y. Cardioprotective actions of grape polyphenols. Nutr. Res. 2008, 28, 729-737. [CrossRef] [PubMed]

120. Ito, J.; Niwa, M. Absolute structures of new hydroxystilbenoids, vitisin C and viniferal, from Vitis vinifera 'Kyohou'. Tetrahedron 1996, 52, 9991-9998. [CrossRef]

121. Da Costa, G.F.; Ognibene, D.T.; da Costa, C.A.; Teixeira, M.T.; Cordeiro, V.D.S.C.; de Bem, G.F.; Moura, A.S.; Resende, A.C.; de Moura, R.S.L. Grape Skin Extract Prevents Development of Hypertension and Altered Lipid Profile in Spontaneously Hypertensive Rats: Role of Oxidative Stress. Prev. Nutr. Food Sci. 2020, 25, 25-31. [CrossRef]

122. Andriambeloson, E.; Stoclet, J.C.; Andriantsitohaina, R. Mechanism of endothelial nitric oxide-dependent vasorelaxation induced by wine polyphenols in rat thoracic aorta. J. Cardiovasc. Pharmacol. 1999, 33, 248-254. [CrossRef] [PubMed]

123. Steinkamp-Fenske, K.; Bollinger, L.; Xu, H.; Yao, Y.; Horke, S.; Förstermann, U.; Li, H. Reciprocal regulation of endothelial nitric-oxide synthase and NADPH oxidase by betulinic acid in human endothelial cells. J. Pharmacol. Exp. Ther. 2007, 322, 836-842. [CrossRef]

124. Othman, R.; Ibrahim, H.; Mohd, M.A.; Awang, K.; Gilani, A.U.; Mustafa, M.R. Vasorelaxant effects of ethyl cinnamate isolated from Kaempferia galanga on smooth muscles of the rat aorta. Planta Med. 2002, 68, 655-657. [CrossRef]

125. De Oliveira, A.P.; Furtado, F.F.; da Silva, M.S.; Tavares, J.F.; Mafra, R.A.; Araújo, D.A.; Cruz, J.S.; de Medeiros, I.A. Calcium channel blockade as a target for the cardiovascular effects induced by the 8 (17), 12E, 14-labdatrien-18-oic acid (labdane-302). Vascul. Pharmacol. 2006, 44, 338-344. [CrossRef]

126. Ribeiro, L.A.A.; Tavares, J.F.; Andrade, N.C.d.; Silva, M.S.d.; Silva, B.A.d. The (8)17,12E,14-labdatrien-18-oic acid (labdane302), labdane-type diterpene isolated from Xylopia langsdorffiana St. Hil. \& Tul. (Annonaceae) relaxes the guinea-pig trachea Ácido (8)17,12E,14-labdatrieno-18-óico (labdano302), diterpeno tipo labdano isolado de Xylopia langsdorffiana St. Hil. \& Tul. (Annonaceae) relaxa a traquéia isolada de cobaia. Rev. Bras. Farmacogn. 2007, 17, 197-203. [CrossRef]

127. Rivedal, E.; Sanner, T. Caffeine and other phosphodiesterase inhibitors are potent inhibitors of the promotional effect of TPA on morphological transformation of hamster embryo cells. Cancer Lett. 1985, 28, 9-17. [CrossRef]

128. Boswell-Smith, V.; Spina, D.; Page, C.P. Phosphodiesterase inhibitors. Br. J. Pharmacol. 2006, 147 (Suppl. 1), S252-S257. [CrossRef] [PubMed]

129. Patay, É.; Bencsik, T.; Papp, N. Phytochemical overview and medicinal importance of Coffea species from the past until now. Asian Pac. J. Trop Med. 2016, 9, 1127-1135. [CrossRef]

130. Shindel, A.W.; Xin, Z.C.; Lin, G.; Fandel, T.M.; Huang, Y.C.; Banie, L.; Breyer, B.N.; Garcia, M.M.; Lin, C.S.; Lue, T.F. Erectogenic and neurotrophic effects of icariin, a purified extract of horny goat weed (Epimedium spp.) in vitro and in vivo. J. Sex. Med. 2010, 7, 1518-1528. [CrossRef] [PubMed]

131. Xu, H.B.; Huang, Z.Q. Icariin enhances endothelial nitric-oxide synthase expression on human endothelial cells in vitro. Vascul. Pharmacol. 2007, 47, 18-24. [CrossRef] [PubMed]

132. Xu, H.B.; Huang, Z.Q. Vasorelaxant effects of icariin on isolated canine coronary artery. J. Cardiovasc. Pharmacol. 2007, 49, 207-213 [CrossRef] [PubMed]

133. Takır, S.; Sezgi, B.; Süzgeç-Selçuk, S.; Eroğlu-Özkan, E.; Beukelman, K.J.; Mat, A.; Uydeş-Doğan, B.S. Endothelium-dependent vasorelaxant effect of Alchemilla vulgaris methanol extract: A comparison with the aqueous extract in rat aorta. Nat. Prod. Res. 2014, 28, 2182-2185. [CrossRef]

134. Takır, S.; Altun, I.H.; Sezgi, B.; Süzgeç-Selçuk, S.; Mat, A.; Uydeş-Doğan, B.S. Vasorelaxant and blood pressure lowering effects of alchemilla vulgaris: A comparative study of methanol and aqueous extracts. Pharmacogn. Mag. 2015, 11, 163-169. [CrossRef]

135. Duarte, J.; Pérez-Vizcaíno, F.; Torres, A.I.; Zarzuelo, A.; Jiménez, J.; Tamargo, J. Vasodilator effects of visnagin in isolated rat vascular smooth muscle. Eur. J. Pharmacol. 1995, 286, 115-122. [CrossRef]

136. Lima, T.C.; de Jesus Souza, R.; da Silva, F.A.; Biavatti, M.W. The genus Calea L.: A review on traditional uses, phytochemistry, and biological activities. Phytother. Res. 2018, 32, 769-795. [CrossRef] [PubMed] 
137. Somoza, B.; de Rojas, V.R.S.; Ortega, T.; Villar, A.M. Vasodilator effects of the extract of the leaves of Cistus populifolius on rat thoracic aorta. Phytother. Res. 1996, 10, 304-308. [CrossRef]

138. Jiang, H.; Xia, Q.; Wang, X.; Song, J.; Bruce, I.C. Luteolin induces vasorelaxion in rat thoracic aorta via calcium and potassium channels. Pharmazie 2005, 60, 444-447. [PubMed]

139. Janbaz, K.H.; Qayyum, A.; Saqib, F.; Imran, I.; Zia-Ul-Haq, M.; de Feo, V. Bronchodilator, vasodilator and spasmolytic activities of Cymbopogon martinii. J. Physiol. Pharmacol. 2014, 65, 859-866.

140. Adaramoye, O.A.; Medeiros, I.A. Endothelium-independent vasodilation induced by kolaviron, a biflavonoid complex from Garcinia kola seeds, in rat superior mesenteric arteries. J. Smooth Muscle Res. 2009, 45, 39-53. [CrossRef]

141. Chericoni, S.; Testai, L.; Calderone, V.; Flamini, G.; Nieri, P.; Morelli, I.; Martinotti, E. The xanthones gentiacaulein and gentiakochianin are responsible for the vasodilator action of the roots of Gentiana kochiana. Planta Med. 2003, 69, 770-772. [CrossRef] [PubMed]

142. Wang, Y.; Shi, J.G.; Wang, M.Z.; Che, C.T.; Yeung, J.H. Vasodilatory actions of xanthones isolated from a Tibetan herb, Halenia elliptica. Phytomedicine 2009, 16, 1144-1150. [CrossRef]

143. Zheoat, A.M.; Gray, A.I.; Igoli, J.O.; Ferro, V.A.; Drummond, R.M. Hibiscus acid from Hibiscus sabdariffa (Malvaceae) has a vasorelaxant effect on the rat aorta. Fitoterapia 2019, 134, 5-13. [CrossRef] [PubMed]

144. Campos, M.G.; Oropeza, M.V.; Villanueva, T.; Aguilar, M.I.; Delgado, G.; Ponce, H.A. Xanthorrhizol induces endotheliumindependent relaxation of rat thoracic aorta. Life Sci. 2000, 67, 327-333. [CrossRef]

145. Kim, B.; Lee, K.; Chinannai, K.S.; Ham, I.; Bu, Y.; Kim, H.; Choi, H.Y. Endothelium-Independent Vasorelaxant Effect of Ligusticum jeholense Root and Rhizoma on Rat Thoracic Aorta. Molecules 2015, 20, 10721-10733. [CrossRef]

146. El Bardai, S.; Morel, N.; Wibo, M.; Fabre, N.; Llabres, G.; Lyoussi, B.; Quetin-Leclercq, J. The vasorelaxant activity of marrubenol and marrubiin from Marrubium vulgare. Planta Med. 2003, 69, 75-77. [CrossRef] [PubMed]

147. El-Bardai, S.; Wibo, M.; Hamaide, M.C.; Lyoussi, B.; Quetin-Leclercq, J.; Morel, N. Characterisation of marrubenol, a diterpene extracted from Marrubium vulgare, as an L-type calcium channel blocker. Br. J. Pharmacol. 2003, 140, 1211-1216. [CrossRef]

148. Rendón-Vallejo, P.; Hernández-Abreu, O.; Vergara-Galicia, J.; Millán-Pacheco, C.; Mejía, A.; Ibarra-Barajas, M.; Estrada-Soto, S. Ex vivo study of the vasorelaxant activity induced by phenanthrene derivatives isolated from Maxillaria densa. J. Nat. Prod. 2012, 75, 2241-2245. [CrossRef]

149. Gilani, A.H.; Mandukhail, S.U.; Iqbal, J.; Yasinzai, M.; Aziz, N.; Khan, A. Antispasmodic and vasodilator activities of Morinda citrifolia root extract are mediated through blockade of voltage dependent calcium channels. BMC Complement. Altern. Med. 2010, 10, 2. [CrossRef] [PubMed]

150. Sanni, D.M.; Fatoki, T.H.; Kolawole, A.O.; Akinmoladun, A.C. Xeronine structure and function: Computational comparative mastery of its mystery. In Silico Pharmacol 2017, 5, 8. [CrossRef]

151. Liew, S.Y.; Mukhtar, M.R.; Hadi, A.H.; Awang, K.; Mustafa, M.R.; Zaima, K.; Morita, H.; Litaudon, M. Naucline, a new indole alkaloid from the bark of Nauclea officinalis. Molecules 2012, 17, 4028-4036. [CrossRef]

152. Ishizuka, M.; Koga, I.; Zaima, K.; Kaneda, T.; Hirasawa, Y.; Hadi, A.H.; Morita, H. Vasorelaxant effects on rat aortic artery by two types of indole alkaloids, naucline and cadamine. J. Nat. Med. 2013, 67, 399-403. [CrossRef]

153. Berrougui, H.; Herrera-Gonzalez, M.D.; Marhuenda, E.; Ettaib, A.; Hmamouchi, M. Relaxant activity of methanolic extract from seeds of Peganum harmala on isolated rat aorta. Therapie 2002, 57, 236-241. [PubMed]

154. Shi, C.C.; Liao, J.F.; Chen, C.F. Comparative study on the vasorelaxant effects of three harmala alkaloids in vitro. Jpn. J. Pharmacol. 2001, 85, 299-305. [CrossRef]

155. Berrougui, H.; Martín-Cordero, C.; Khalil, A.; Hmamouchi, M.; Ettaib, A.; Marhuenda, E.; Herrera, M.D. Vasorelaxant effects of harmine and harmaline extracted from Peganum harmala L. seeds in isolated rat aorta. Pharmacol. Res. 2006, 54, 150-157. [CrossRef] [PubMed]

156. Lin, L.L.; Huang, F.; Chen, S.B.; Yang, D.J.; Chen, S.L.; Yang, J.S.; Xiao, P.G. Xanthones from the roots of Polygala caudata and their antioxidation and vasodilatation activities in vitro. Planta Med. 2005, 71, 372-375. [CrossRef]

157. Fang, L.H.; Mu, Y.M.; Lin, L.L.; Xiao, P.G.; Du, G.H. Vasorelaxant effect of euxanthone in the rat thoracic aorta. Vascul. Pharmacol. 2006, 45, 96-101. [CrossRef]

158. Lee, K.; Ham, I.; Yang, G.; Lee, M.; Bu, Y.; Kim, H.; Choi, H.Y. Vasorelaxant effect of Prunus yedoensis bark. BMC Complement. Altern. Med. 2013, 13, 31. [CrossRef] [PubMed]

159. Kim, B.; Jo, C.; Choi, H.Y.; Lee, K. Prunetin Relaxed Isolated Rat Aortic Rings by Blocking Calcium Channels. Molecules 2018, 23, 2372. [CrossRef] [PubMed]

160. Ghayur, M.N.; Gilani, A.H. Studies on cardio-suppressant, vasodilator and tracheal relaxant effects of Sarcococca saligna. Arch. Pharm. Res. 2006, 29, 990-997. [CrossRef]

161. Sargazi Zadeh, G.; Panahi, N. Endothelium-independent vasorelaxant activity of Trachyspermum ammi essential oil on rat aorta. Clin. Exp. Hypertens. 2017, 39, 133-138. [CrossRef] [PubMed]

162. Zhang, W.B.; Chen, C.X.; Sim, S.M.; Kwan, C.Y. In vitro vasodilator mechanisms of the indole alkaloids rhynchophylline and isorhynchophylline, isolated from the hook of Uncaria rhynchophylla (Miquel). Naunyn Schmiedebergs Arch. Pharmacol. 2004, 369, 232-238. [CrossRef] [PubMed]

163. Horie, S.; Yano, S.; Aimi, N.; Sakai, S.; Watanabe, K. Effects of hirsutine, an antihypertensive indole alkaloid from Uncaria rhynchophylla, on intracellular calcium in rat thoracic aorta. Life Sci. 1992, 50, 491-498. [CrossRef] 
164. Hernández-Abreu, O.; Castillo-España, P.; León-Rivera, I.; Ibarra-Barajas, M.; Villalobos-Molina, R.; González-Christen, J.; Vergara-Galicia, J.; Estrada-Soto, S. Antihypertensive and vasorelaxant effects of tilianin isolated from Agastache mexicana are mediated by NO/cGMP pathway and potassium channel opening. Biochem. Pharmacol. 2009, 78, 54-61. [CrossRef]

165. Flores-Flores, A.; Hernández-Abreu, O.; Rios, M.Y.; León-Rivera, I.; Aguilar-Guadarrama, B.; Castillo-España, P.; Perea-Arango, I.; Estrada-Soto, S. Vasorelaxant mode of action of dichloromethane-soluble extract from Agastache mexicana and its main bioactive compounds. Pharm. Biol. 2016, 54, 2807-2813. [CrossRef] [PubMed]

166. Wang, Z.T.; Lau, C.W.; Chan, F.L.; Yao, X.; Chen, Z.Y.; He, Z.D.; Huang, Y. Vasorelaxant effects of cardamonin and alpinetin from Alpinia henryi K. Schum. J. Cardiovasc. Pharmacol. 2001, 37, 596-606. [CrossRef] [PubMed]

167. Fusi, F.; Cavalli, M.; Mulholland, D.; Crouch, N.; Coombes, P.; Dawson, G.; Bova, S.; Sgaragli, G.; Saponara, S. Cardamonin is a bifunctional vasodilator that inhibits $\mathrm{Ca}(\mathrm{v}) 1.2$ current and stimulates $\mathrm{K}(\mathrm{Ca}) 1.1$ current in rat tail artery myocytes. J. Pharmacol. Exp. Ther. 2010, 332, 531-540. [CrossRef]

168. Channa, S.; Dar, A.; Ahmed, S. Evaluation of Alstonia scholaris leaves for broncho-vasodilatory activity. J. Ethnopharmacol. 2005, 97, 469-476. [CrossRef] [PubMed]

169. Bello, I.; Usman, N.S.; Mahmud, R.; Asmawi, M.Z. Mechanisms underlying the antihypertensive effect of Alstonia scholaris. J. Ethnopharmacol. 2015, 175, 422-431. [CrossRef]

170. Arai, H.; Zaima, K.; Mitsuta, E.; Tamamoto, H.; Saito, A.; Hirasawa, Y.; Rahman, A.; Kusumawati, I.; Zaini, N.C.; Morita, H. Alstiphyllanines I-O, ajmaline type alkaloids from Alstonia macrophylla showing vasorelaxant activity. Bioorg. Med. Chem. 2012, 20, 3454-3459. [CrossRef]

171. Ozolua, R.I.; Adejayan, A.; Aigbe, O.P.; Uwaya, D.O.; Argawal, A. Some characteristic relaxant effects of aqueous leaf extract of Andrographis paniculata and andrographolide on guinea pig tracheal rings. Niger. J. Physiol. Sci. 2011, 26, 119-124.

172. Zhang, C.Y.; Tan, B.K. Hypotensive activity of aqueous extract of Andrographis paniculata in rats. Clin. Exp. Pharmacol. Physiol. 1996, 23, 675-678. [CrossRef]

173. Zhang, C.Y.; Tan, B.K. Vasorelaxation of rat thoracic aorta caused by 14-deoxyandrographolide. Clin. Exp. Pharmacol. Physiol. 1998, 25, 424-429. [CrossRef] [PubMed]

174. Awang, K.; Abdullah, N.H.; Hadi, A.H.; Fong, Y.S. Cardiovascular activity of labdane diterpenes from Andrographis paniculata in isolated rat hearts. J. Biomed. Biotechnol. 2012, 2012, 876458. [CrossRef] [PubMed]

175. Lee, K.; Shin, M.S.; Ham, I.; Choi, H.Y. Investigation of the mechanisms of Angelica dahurica root extract-induced vasorelaxation in isolated rat aortic rings. BMC Complement. Altern. Med. 2015, 15, 395. [CrossRef] [PubMed]

176. Deng, G.G.; Wei, W.; Yang, X.W.; Zhang, Y.B.; Xu, W.; Gong, N.B.; Lü, Y.; Wang, F.F. New coumarins from the roots of Angelica dahurica var. formosana cv. Chuanbaizhi and their inhibition on NO production in LPS-activated RAW264.7 cells. Fitoterapia 2015, 101, 194-200. [CrossRef]

177. He, J.Y.; Zhang, W.; He, L.C.; Cao, Y.X. Imperatorin induces vasodilatation possibly via inhibiting voltage dependent calcium channel and receptor-mediated Ca2+ influx and release. Eur. J. Pharmacol. 2007, 573, 170-175. [CrossRef]

178. Nie, H.; Meng, L.Z.; Zhou, J.Y.; Fan, X.F.; Luo-, Y.; Zhang, G.W. Imperatorin is responsible for the vasodilatation activity of Angelica Dahurica var. Formosana regulated by nitric oxide in an endothelium-dependent manner. Chin. J. Integr. Med. 2009, 15, 442-447. [CrossRef] [PubMed]

179. Rhyu, M.R.; Kim, J.H.; Kim, E.Y. Radix angelica elicits both nitric oxide-dependent and calcium influx-mediated relaxation in rat aorta. J. Cardiovasc. Pharmacol. 2005, 46, 99-104. [CrossRef]

180. Matsuura, M.; Kimura, Y.; Nakata, K.; Baba, K.; Okuda, H. Artery relaxation by chalcones isolated from the roots of Angelica keiskei. Planta Med. 2001, 67, 230-235. [CrossRef] [PubMed]

181. Zhang, Y.H.; Park, Y.S.; Kim, T.J.; Fang, L.H.; Ahn, H.Y.; Hong, J.T.; Kim, Y.; Lee, C.K.; Yun, Y.P. Endothelium-dependent vasorelaxant and antiproliferative effects of apigenin. Gen. Pharmacol. 2000, 35, 341-347. [CrossRef]

182. Ko, F.N.; Huang, T.F.; Teng, C.M. Vasodilatory action mechanisms of apigenin isolated from Apium graveolens in rat thoracic aorta. Biochim. Biophys. Acta 1991, 1115, 69-74. [CrossRef]

183. Ma, X.; He, D.; Ru, X.; Chen, Y.; Cai, Y.; Bruce, I.C.; Xia, Q.; Yao, X.; Jin, J. Apigenin, a plant-derived flavone, activates transient receptor potential vanilloid 4 cation channel. Br. J. Pharmacol. 2012, 166, 349-358. [CrossRef]

184. Dar, A.; Channa, S. Calcium antagonistic activity of Bacopa monniera on vascular and intestinal smooth muscles of rabbit and guinea-pig. J. Ethnopharmacol. 1999, 66, 167-174. [CrossRef]

185. Channa, S.; Dar, A.; Yaqoob, M.; Anjum, S.; Sultani, Z. Broncho-vasodilatory activity of fractions and pure constituents isolated from Bacopa monniera. J. Ethnopharmacol. 2003, 86, 27-35. [CrossRef]

186. Kamkaew, N.; Paracha, T.U.; Ingkaninan, K.; Waranuch, N.; Chootip, K. Vasodilatory Effects and Mechanisms of Action of. Molecules 2019, 24, 2243. [CrossRef]

187. Kamkaew, N.; Scholfield, C.N.; Ingkaninan, K.; Maneesai, P.; Parkington, H.C.; Tare, M.; Chootip, K. Bacopa monnieri and its constituents is hypotensive in anaesthetized rats and vasodilator in various artery types. J. Ethnopharmacol. 2011, 137, 790-795. [CrossRef]

188. Ko, W.H.; Yao, X.Q.; Lau, C.W.; Law, W.I.; Chen, Z.Y.; Kwok, W.; Ho, K.; Huang, Y. Vasorelaxant and antiproliferative effects of berberine. Eur. J. Pharmacol. 2000, 399, 187-196. [CrossRef] 
189. Neag, M.A.; Mocan, A.; Echeverría, J.; Pop, R.M.; Bocsan, C.I.; Crişan, G.; Buzoianu, A.D. Berberine: Botanical Occurrence, Traditional Uses, Extraction Methods, and Relevance in Cardiovascular, Metabolic, Hepatic, and Renal Disorders. Front. Pharmacol. 2018, 9, 557. [CrossRef] [PubMed]

190. Moore, R.J.; Jackson, K.G.; Minihane, A.M. Green tea (Camellia sinensis) catechins and vascular function. Br. J. Nutr. 2009, 102, 1790-1802. [CrossRef] [PubMed]

191. Ghayur, M.N.; Khan, H.; Gilani, A.H. Antispasmodic, bronchodilator and vasodilator activities of (+)-catechin, a naturally occurring flavonoid. Arch. Pharm. Res. 2007, 30, 970-975. [CrossRef]

192. Aggio, A.; Grassi, D.; Onori, E.; D’Alessandro, A.; Masedu, F.; Valenti, M.; Ferri, C. Endothelium/nitric oxide mechanism mediates vasorelaxation and counteracts vasoconstriction induced by low concentration of flavanols. Eur. J. Nutr. 2013, 52, 263-272. [CrossRef] [PubMed]

193. Alvarez, E.; Campos-Toimil, M.; Justiniano-Basaran, H.; Lugnier, C.; Orallo, F. Study of the mechanisms involved in the vasorelaxation induced by (-)-epigallocatechin-3-gallate in rat aorta. Br. J. Pharmacol. 2006, 147, 269-280. [CrossRef] [PubMed]

194. Romano, M.R.; Lograno, M.D. Epigallocatechin-3-gallate relaxes the isolated bovine ophthalmic artery: Involvement of phosphoinositide 3-kinase-Akt-nitric oxide/cGMP signalling pathway. Eur. J. Pharmacol. 2009, 608, 48-53. [CrossRef]

195. Assaidi, A.; Dib, I.; Tits, M.; Angenot, L.; Bellahcen, S.; Bouanani, N.; Legssyer, A.; Aziz, M.; Mekhfi, H.; Bnouham, M.; et al. Chenopodium ambrosioides induces an endothelium-dependent relaxation of rat isolated aorta. J. Integr. Med. 2019, 17, 115-124. [CrossRef]

196. Jiang, H.D.; Cai, J.; Xu, J.H.; Zhou, X.M.; Xia, Q. Endothelium-dependent and direct relaxation induced by ethyl acetate extract from Flos Chrysanthemi in rat thoracic aorta. J. Ethnopharmacol. 2005, 101, 221-226. [CrossRef] [PubMed]

197. Affuso, F.; Mercurio, V.; Fazio, V.; Fazio, S. Cardiovascular and metabolic effects of Berberine. World J. Cardiol. 2010, 2, 71-77. [CrossRef]

198. Wang, Y.; Huang, Y.; Lam, K.S.; Li, Y.; Wong, W.T.; Ye, H.; Lau, C.W.; Vanhoutte, P.M.; Xu, A. Berberine prevents hyperglycemiainduced endothelial injury and enhances vasodilatation via adenosine monophosphate-activated protein kinase and endothelial nitric oxide synthase. Cardiovasc. Res. 2009, 82, 484-492. [CrossRef] [PubMed]

199. Gong, L.L.; Fang, L.H.; Qin, H.L.; Lv, Y.; Du, G.H. Analysis of the mechanisms underlying the vasorelaxant action of coptisine in rat aortic rings. Am. J. Chin. Med. 2012, 40, 309-320. [CrossRef]

200. Tan, H.L.; Chan, K.G.; Pusparajah, P.; Duangjai, A.; Saokaew, S.; Mehmood Khan, T.; Lee, L.H.; Goh, B.H. Rhizoma Coptidis: A Potential Cardiovascular Protective Agent. Front. Pharmacol. 2016, 7, 362. [CrossRef]

201. Qiao, M.M.; Liu, F.; Liu, Y.; Guo, L.; Zhou, Q.M.; Peng, C.; Xiong, L. Curcumane C and ( \pm )-curcumane D, an unusual secocadinane sesquiterpenoid and a pair of unusual nor-bisabolane enantiomers with significant vasorelaxant activity from Curcuma longa. Bioorg. Chem. 2019, 92, 103275. [CrossRef]

202. Yu, S.M.; Cheng, Z.J.; Kuo, S.C. Endothelium-dependent relaxation of rat aorta by butein, a novel cyclic AMP-specific phosphodiesterase inhibitor. Eur. J. Pharmacol. 1995, 280, 69-77. [CrossRef]

203. Yu, S.M.; Kuo, S.C. Vasorelaxant effect of isoliquiritigenin, a novel soluble guanylate cyclase activator, in rat aorta. Br. J. Pharmacol. 1995, 114, 1587-1594. [CrossRef] [PubMed]

204. Ma, F.Y.; Luo, M.; Zhao, C.J.; Li, C.Y.; Wang, W.; Gu, C.B.; Wei, Z.F.; Zu, Y.G.; Fu, Y.J. Simple and efficient preparation of biochanin A and genistein from Dalbergia odorifera T. Chen leaves using macroporous resin followed by flash chromatography. Sep. Purif. Technol. 2013, 120, 310-318. [CrossRef]

205. Kumar, T.; Sharma, M.; Rana, A.; Lingaraju, M.C.; Parida, S.; Kumar, D.; Singh, T.U. Biochanin-A elicits relaxation in coronary artery of goat through different mechanisms. Res. Vet. Sci 2020, 131, 206-214. [CrossRef]

206. Wang, H.P.; Mei, R.H.; Li, X.Y.; Zhao, M.H.; Lu, Y.; Xia, Q.; Bruce, I. Endothelium-independent Vasorelaxant Effect of the Phyto-oestrogen Biochanin A on Rat Thoracic Aorta. In Proceedings of the 2005 IEEE Engineering in Medicine and Biology 27th Annual Conference, Shanghai, China, 17-18 January 2006; Volume 2005, pp. 2244-2247. [CrossRef]

207. Choi, S.; Jung, W.S.; Cho, N.S.; Ryu, K.H.; Jun, J.Y.; Shin, B.C.; Chung, J.H.; Yeum, C.H. Mechanisms of phytoestrogen biochanin A-induced vasorelaxation in renovascular hypertensive rats. Kidney Res. Clin. Pract. 2014, 33, 181-186. [CrossRef]

208. Migkos, T.; Pourová, J.; Vopršalová, M.; Auger, C.; Schini-Kerth, V.; Mladěnka, P. Biochanin A, the Most Potent of 16 Isoflavones, Induces Relaxation of the Coronary Artery Through the Calcium Channel and cGMP-dependent Pathway. Planta Med. 2020, 86, 708-716. [CrossRef]

209. Sá, R.e.C.; Almeida, R.N.; Bhattacharyya, J. Pharmaceutical properties and toxicology of Dioclea grandiflora. Pharm. Biol. 2013, 51, 659-667. [CrossRef]

210. Trigueiro, F.; Cortes, S.F.; Almeida, R.N.; Lemos, V.S. Endothelium-independent vasorelaxant effect of dioclein, a new flavonoid isolated from Dioclea grandiflora, in the rat aorta. J. Pharm. Pharmacol. 2000, 52, 1431-1434. [CrossRef]

211. Côrtes, S.F.; Rezende, B.A.; Corriu, C.; Medeiros, I.A.; Teixeira, M.M.; Lopes, M.J.; Lemos, V.S. Pharmacological evidence for the activation of potassium channels as the mechanism involved in the hypotensive and vasorelaxant effect of dioclein in rat small resistance arteries. Br. J. Pharmacol. 2001, 133, 849-858. [CrossRef] [PubMed]

212. Gonçalves, R.L.; Lugnier, C.; Keravis, T.; Lopes, M.J.; Fantini, F.A.; Schmitt, M.; Cortes, S.F.; Lemos, V.S. The flavonoid dioclein is a selective inhibitor of cyclic nucleotide phosphodiesterase type 1 (PDE1) and a cGMP-dependent protein kinase (PKG) vasorelaxant in human vascular tissue. Eur. J. Pharmacol. 2009, 620, 78-83. [CrossRef] [PubMed] 
213. Lemos, V.S.; Côrtes, S.F.; dos Santos, M.H.; Ellena, J.; Moreira, M.E.; Doriguetto, A.C. Structure and vasorelaxant activity of floranol, a flavonoid isolated from the roots of Dioclea grandiflora. Chem. Biodivers. 2006, 3, 635-645. [CrossRef]

214. Marques, A.M.; Provance, D.W.; Kaplan, M.A.C.; Figueiredo, M.R. Echinodorus grandiflorus: Ethnobotanical, phytochemical and pharmacological overview of a medicinal plant used in Brazil. Food Chem. Toxicol. 2017, 109, 1032-1047. [CrossRef]

215. Tibiriçá, E.; Almeida, A.; Caillleaux, S.; Pimenta, D.; Kaplan, M.A.; Lessa, M.A.; Figueiredo, M.R. Pharmacological mechanisms involved in the vasodilator effects of extracts from Echinodorus grandiflorus. J. Ethnopharmacol. 2007, 111, 50-55. [CrossRef] [PubMed]

216. Prando, T.B.; Barboza, L.N.; Araújo, V.e.O.; Gasparotto, F.M.; de Souza, L.M.; Lourenço, E.L.; Gasparotto Junior, A. Involvement of bradykinin B2 and muscarinic receptors in the prolonged diuretic and antihypertensive properties of Echinodorus grandiflorus (Cham. \& Schltdl.) Micheli. Phytomedicine 2016, 23, 1249-1258. [CrossRef]

217. Peng, H.; Xing, Y.; Gao, L.; Zhang, L.; Zhang, G. Simultaneous separation of apigenin, luteolin and rosmarinic acid from the aerial parts of the copper-tolerant plant Elsholtzia splendens. Environ. Sci. Pollut. Res. Int. 2014, 21, 8124-8132. [CrossRef] [PubMed]

218. Wang, H.P.; Lu, J.F.; Zhang, G.L.; Li, X.Y.; Peng, H.Y.; Lu, Y.; Zhao, L.; Ye, Z.G.; Bruce, I.C.; Xia, Q.; et al. Endothelium-dependent and -independent vasorelaxant actions and mechanisms induced by total flavonoids of Elsholtzia splendens in rat aortas. Environ. Toxicol. Pharmacol. 2014, 38, 453-459. [CrossRef]

219. Ferreira, H.C.; Serra, C.P.; Endringer, D.C.; Lemos, V.S.; Braga, F.C.; Cortes, S.F. Endothelium-dependent vasodilation induced by Hancornia speciosa in rat superior mesenteric artery. Phytomedicine 2007, 14, 473-478. [CrossRef] [PubMed]

220. Chan, S.S.; Choi, A.O.; Jones, R.L.; Lin, G. Mechanisms underlying the vasorelaxing effects of butylidenephthalide, an active constituent of Ligusticum chuanxiong, in rat isolated aorta. Eur. J. Pharmacol. 2006, 537, 111-117. [CrossRef]

221. Cao, Y.X.; Zhang, W.; He, J.Y.; He, L.C.; Xu, C.B. Ligustilide induces vasodilatation via inhibiting voltage dependent calcium channel and receptor-mediated Ca2+ influx and release. Vascul. Pharmacol. 2006, 45, 171-176. [CrossRef] [PubMed]

222. Chan, S.S.; Cheng, T.Y.; Lin, G. Relaxation effects of ligustilide and senkyunolide A, two main constituents of Ligusticum chuanxiong, in rat isolated aorta. J. Ethnopharmacol. 2007, 111, 677-680. [CrossRef] [PubMed]

223. Kim, E.Y.; Kim, J.H.; Rhyu, M.R. Endothelium-independent vasorelaxation by Ligusticum wallichii in isolated rat aorta: Comparison of a butanolic fraction and tetramethylpyrazine, the main active component of Ligusticum wallichii. Biol. Pharm. Bull. 2010, 33, 1360-1363. [CrossRef]

224. Guedes, D.N.; Silva, D.F.; Barbosa-Filho, J.M.; de Medeiros, I.A. Endothelium-dependent hypotensive and vasorelaxant effects of the essential oil from aerial parts of Mentha x villosa in rats. Phytomedicine 2004, 11, 490-497. [CrossRef] [PubMed]

225. Guedes, D.N.; Silva, D.F.; Barbosa-Filho, J.M.; Medeiros, I.A. Muscarinic agonist properties involved in the hypotensive and vasorelaxant responses of rotundifolone in rats. Planta Med. 2002, 68, 700-704. [CrossRef] [PubMed]

226. Guedes, D.N.; Silva, D.F.; Barbosa-Filho, J.M.; Medeiros, I.A. Calcium antagonism and the vasorelaxation of the rat aorta induced by rotundifolone. Braz. J. Med. Biol. Res. 2004, 37, 1881-1887. [CrossRef]

227. Silva, D.F.; Araújo, I.G.; Albuquerque, J.G.; Porto, D.L.; Dias, K.L.; Cavalcante, K.V.; Veras, R.C.; Nunes, X.P.; Barbosa-Filho, J.M.; Araújo, D.A.; et al. Rotundifolone-induced relaxation is mediated by $\mathrm{BK}(\mathrm{Ca})$ channel activation and $\mathrm{Ca}(\mathrm{v})$ channel inactivation. Basic Clin. Pharmacol. Toxicol. 2011, 109, 465-475. [CrossRef] [PubMed]

228. Dongmo, A.; Kamanyi, M.A.; Tan, P.V.; Bopelet, M.; Vierling, W.; Wagner, H. Vasodilating properties of the stem bark extract of Mitragyna ciliata in rats and guinea pigs. Phytother. Res. 2004, 18, 36-39. [CrossRef] [PubMed]

229. Zaima, K.; Takeyama, Y.; Koga, I.; Saito, A.; Tamamoto, H.; Azziz, S.S.; Mukhtar, M.R.; Awang, K.; Hadi, A.H.; Morita, H. Vasorelaxant effect of isoquinoline derivatives from two species of Popowia perakensis and Phaeanthus crassipetalus on rat aortic artery. J. Nat. Med. 2012, 66, 421-427. [CrossRef]

230. Senejoux, F.; Girard-Thernier, C.; Berthelot, A.; Bévalot, F.; Demougeot, C. New insights into the mechanisms of the vasorelaxant effects of apocynin in rat thoracic aorta. Fundam. Clin. Pharmacol. 2013, 27, 262-270. [CrossRef]

231. Perassa, L.A.; Graton, M.E.; Potje, S.R.; Troiano, J.A.; Lima, M.S.; Vale, G.T.; Pereira, A.A.; Nakamune, A.C.; Sumida, D.H.; Tirapelli, C.R.; et al. Apocynin reduces blood pressure and restores the proper function of vascular endothelium in SHR. Vascul. Pharmacol. 2016, 87, 38-48. [CrossRef] [PubMed]

232. Luna-Vázquez, F.J.; Ibarra-Alvarado, C.; Rojas-Molina, A.; Romo-Mancillas, A.; López-Vallejo, F.H.; Solís-Gutiérrez, M.; RojasMolina, J.I.; Rivero-Cruz, F. Role of Nitric Oxide and Hydrogen Sulfide in the Vasodilator Effect of Ursolic Acid and Uvaol from Black Cherry Prunus serotina Fruits. Molecules 2016, 21, 78. [CrossRef] [PubMed]

233. Park, J.Y.; Shin, H.K.; Lee, Y.J.; Choi, Y.W.; Bae, S.S.; Kim, C.D. The mechanism of vasorelaxation induced by Schisandra chinensis extract in rat thoracic aorta. J. Ethnopharmacol. 2009, 121, 69-73. [CrossRef]

234. Park, J.Y.; Shin, H.K.; Choi, Y.W.; Lee, Y.J.; Bae, S.S.; Han, J.; Kim, C.D. Gomisin A induces Ca2+-dependent activation of eNOS in human coronary artery endothelial cells. J. Ethnopharmacol. 2009, 125, 291-296. [CrossRef] [PubMed]

235. Park, J.Y.; Lee, S.J.; Yun, M.R.; Seo, K.W.; Bae, S.S.; Park, J.W.; Lee, Y.J.; Shin, W.J.; Choi, Y.W.; Kim, C.D. Gomisin A from Schisandra chinensis induces endothelium-dependent and direct relaxation in rat thoracic aorta. Planta Med. 2007, 73, 1537-1542. [CrossRef]

236. Ding, L.; Jia, C.; Zhang, Y.; Wang, W.; Zhu, W.; Chen, Y.; Zhang, T. Baicalin relaxes vascular smooth muscle and lowers blood pressure in spontaneously hypertensive rats. Biomed. Pharmacother. 2019, 111, 325-330. [CrossRef]

237. Lin, Y.L.; Dai, Z.K.; Lin, R.J.; Chu, K.S.; Chen, I.J.; Wu, J.R.; Wu, B.N. Baicalin, a flavonoid from Scutellaria baicalensis Georgi, activates large-conductance $\mathrm{Ca}^{2+}$-activated $\mathrm{K}^{+}$channels via cyclic nucleotide-dependent protein kinases in mesenteric artery. Phytomedicine 2010, 17, 760-770. [CrossRef] [PubMed] 
238. Paredes, A.; Palacios, J.; Quispe, C.; Nwokocha, C.R.; Morales, G.; Kuzmicic, J.; Cifuentes, F. Hydroalcoholic extract and pure compounds from Senecio nutans Sch. Bip (Compositae) induce vasodilation in rat aorta through endothelium-dependent and independent mechanisms. J. Ethnopharmacol. 2016, 192, 99-107. [CrossRef]

239. Auger, C.; Chabert, P.; Lugnier, C.; Mushtaq, M.N.; Schini-Kerth, V.B. Mechanisms underlying vasorelaxation induced in the porcine coronary arteries by Thymus linearis, Benth. J. Ethnopharmacol. 2018, 225, 211-219. [CrossRef]

240. Getiye, Y.; Tolessa, T.; Engidawork, E. Antihypertensive activity of $80 \%$ methanol seed extract of Calpurnia aurea (Ait.) Benth. subsp. aurea (Fabaceae) is mediated through calcium antagonism induced vasodilation. J. Ethnopharmacol 2016, 189, 99-106. [CrossRef]

241. Khan, M.; Gilani, A.H. Studies on Blood Pressure Lowering, Vasodilator and Cardiac Suppressant Activities of Vitex negundo: Involvement of $\mathrm{K}+$ Channel Activation and Ca++ Channel Blockade. Int. J. Pharmacol. 2015, 11, 137-142. [CrossRef]

242. Dongmo, A.B.; Ndom, J.C.; Massoma, L.D.; Dzikouk, D.G.; Fomani, M.; Bissoue, N.; Kamanyi, A.; Vierling, W. Vasodilating effect of the root bark extract of Ficus saussureana on guinea pig aorta. Pharmaceutical. Biol. 2003, 41, 371-374.

243. Kim, B.; Kim, K.W.; Lee, S.; Jo, C.; Lee, K.; Ham, I.; Choi, H.Y. Endothelium-dependent vasorelaxant effect of Prunus persica branch on isolated rat thoracic aorta. Nutrients 2019,11, 1816. [CrossRef]

244. Ramón Sánchez de Rojas, V.; Somoza, B.; Ortega, T.; Villar, A.M.; Tejerina, T. Vasodilatory effect in rat aorta of eriodictyol obtained from Satureja obovata. Planta Med. 1999, 65, 234-238. [CrossRef]

245. Derojas, V.R.S.; Ortega, T.; Villar, A. Pharmacological activity of the extracts of 2 Satureja obovata varieties on isolated smoothmuscle preparations. Phytother. Res. 1994, 8, 212-217. [CrossRef]

246. Ch`ng, Y.S.; Loh, Y.C.; Tan, C.S.; Ahmad, M.; Asmawi, M.Z.; Wan Omar, W.M.; Yam, M.F. Vasorelaxant properties of Vernonia amygdalina ethanol extract and its possible mechanism. Pharm. Biol. 2017, 55, 2083-2094. [CrossRef] [PubMed]

247. Gkaliagkousi, E.; Gavriilaki, E.; Triantafyllou, A.; Douma, S. Clinical Significance of Endothelial Dysfunction in Essential Hypertension. Curr. Hypertens. Rep. 2015, 17, 85. [CrossRef] [PubMed] 